\title{
SELF-STUDY EXPLORING PEDAGOGY TO ENGAGE COMMUNITY COLLEGE STUDENTS IN CHEMISTRY
}

\author{
A Dissertation submitted to the faculty of \\ San Francisco State University \\ In partial fulfillment of \\ the requirements for \\ the Degree
}

Doctor of Education

In

Educational Leadership

by

Harjot Kaur Sawhney

San Francisco, California

January 2020 
Copyright by

Harjot Kaur Sawhney

2020 


\section{CERTIFICATION OF APPROVAL}

I certify that I have read Self-Study Exploring Pedagogy to Engage Community College Students in Chemistry by Harjot Sawhney, and that in my opinion this work meets the criteria for approving a thesis submitted in partial fulfillment of the requirement for the degree Doctorate in Education in Educational Leadership at San Francisco State University.

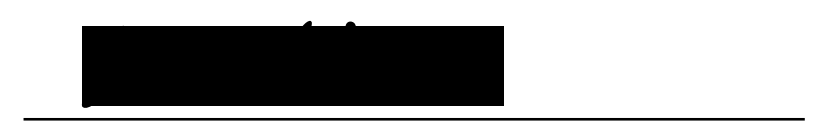

Stephanie Sisk-Hilton, Ph.D.

Professor

Elementary Education

San Francisco State University

Barbara Henderson, Ph.D.

Professor

Elementary Education

San Francisco State University

Lawrence Horvath, Ph.D.

Associate Professor

CSME

San Francisco State University 


\title{
SELF-STUDY EXPLORING PEDAGOGY TO ENGAGE COMMUNITY COLLEGE STUDENTS IN CHEMISTRY
}

\author{
Harjot Kaur Sawhney \\ San Francisco, California
}

2020

The teaching pedagogy is one of the reasons for student attrition in first-year introductory STEM courses in a community college. The purpose of this research was to focus on my instructional practices in introductory chemistry to better incorporate student perspectives. This self-study provided insights into what STEM instructors can do in a classroom to support learning and persistence. This study used a qualitative analysis with a deductive approach. Data was drawn from pretest and posttest surveys, reflected exit tickets, interviews, and field notes. This study adds to existing research that culturally responsive practices, in combination with active learning strategies, are useful in student learning. Findings suggest that students appreciated collaborative learning and the use of relatable examples when learning new concepts, although they also resisted some moves toward active learning in ways that showed reliance on more traditional approaches. Instructors, deans, and administrators could provide professional training in teaching pedagogy and financial incentives to promote interactive strategies and dissuade faculty from using traditional pedagogy to bring equity, inclusion, and social justice.

I certify that the Abstract is a correct representation of the content of this dissertation.

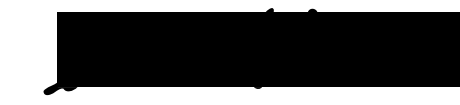

Stephanie Sisk-Hilton, Ph.D.

Date

Chair, Dissertation Committee 


\section{ACKNOWLEDGMENTS}

I am thankful to Waheguru (God) for supporting me at every step of this process.

I am dedicating this work to my son, Sanjam Sawhney. You are my motivation!

I am thankful

To my parents for providing me equity in education.

To my committee, Dr. Stephanie Sisk-Hilton, Dr. Barbara Henderson, and Dr. Lawrence Horvath, for your critique and support.

To Dr. Vanson Nyugen for being my mentor.

To my family and friends. You made sure that I take occasional breaks from my research and join you in fun-filled activities. 


\section{TABLE OF CONTENTS}

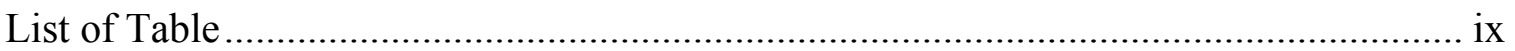

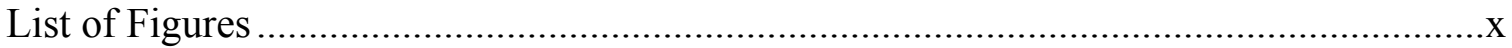

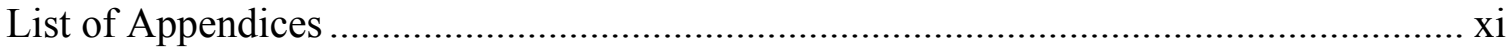

Chapter One: Introduction ..................................................................................

Research Scholar Experience...........................................................................

Inequity in Community College STEM Outcomes.............................................6

Inequitable college completion rates …............................................. 7

Inequitable college completion rates in STEM .........................................8

High attrition of underserved students in STEM ...................................9

Role of Faculty in Student Outcomes in STEM .............................................. 10

Impact of Pedagogical Stance on STEM learning ............................................15

The problem of Practice and Research Questions ..........................................16

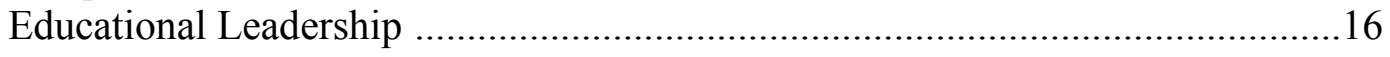

Chapter Two: Literature Review .............................................................................19

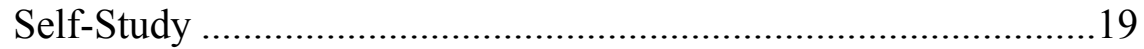

Culturally Responsive Practices (CRP) .....................................19

Active Learning Strategies (ALS) ........................................20

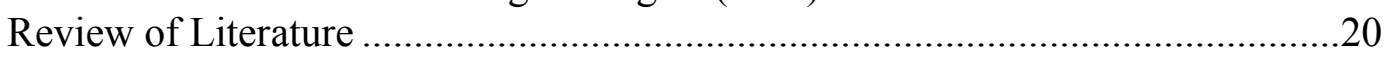

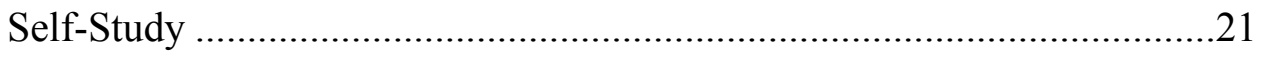

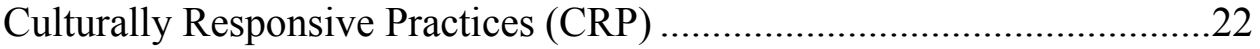

Instructor Qualities ...............................................................23

Caring and approachable ..............................................23

Promotes reasoning ................................................24

Power sharing ...............................................................25

Examples, demos ......................................................25

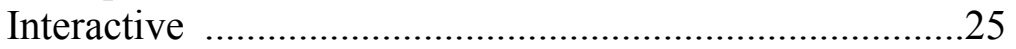

Receptive to questions ..................................................26

Relatable examples ...........................................................26

Classroom structures/community building ................................27

Classroom Environment ..............................................27

Collaborative Learning .................................................28

Recognizing a student's strength ...................................29

Active Learning Strategies (ALS) ..................................................29

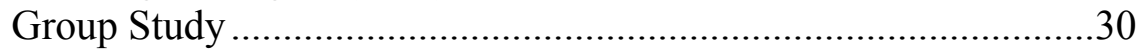

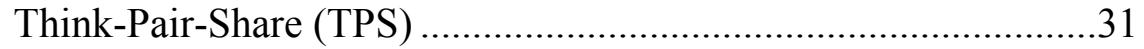

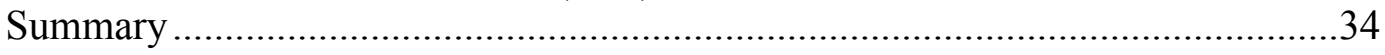


Chapter Three: Methodology ………………………….............................................36

The problem of Practice and Research Questions .................................................37

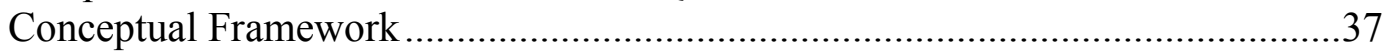

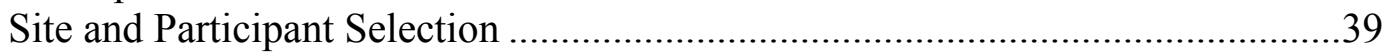

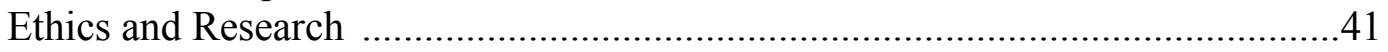

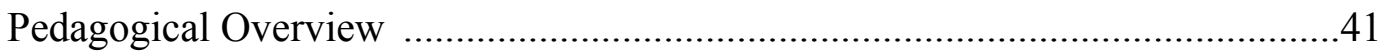

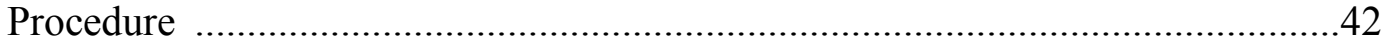

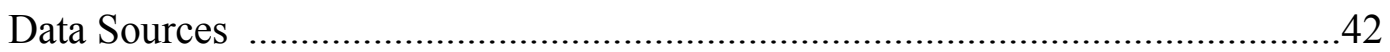

Potential biases based on positionality ....................................................4

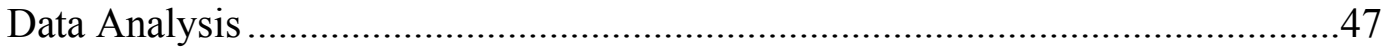

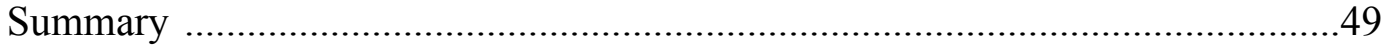

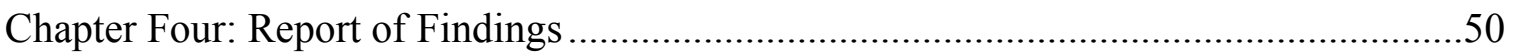

The Challenge of Stoichiometry in Introductory Chemistry ................................51

The Teaching of Stoichiometry and My Own Development as An Instructor .....53

Culturally Responsive Practices (CRP) and Active Learning Strategies (ALS) to

Support the Learning of Stoichiometry.............................................................56

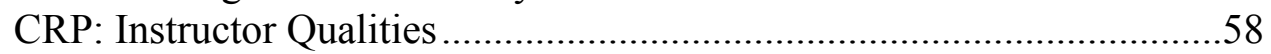

CRP: Relatable Examples ....................................................................59

CRP: Classroom Environment/Community Building .................................61

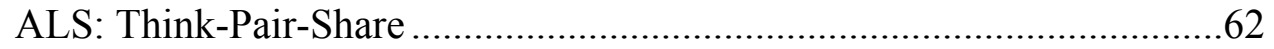

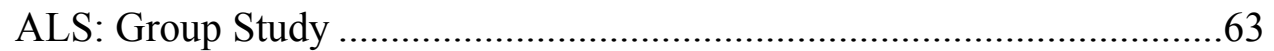

Analysis of Student Response to Culturally Responsive Practices and Active

Learning Strategies in Stoichiometry Unit ......................................................64

Analysis of Student Response to CRP and ALS..............................................70

Points of connection - CRP: Relatable Examples ......................................71

Points of connection - CRP: Instructor Qualities .....................................73

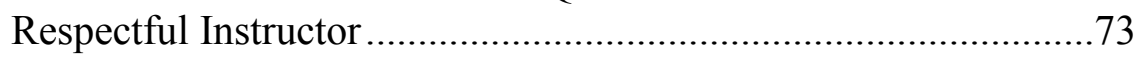

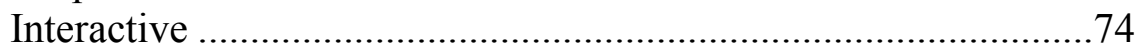

Points of connection - CRP: Classroom Environment/Community

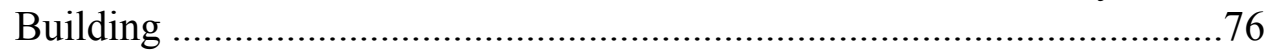

Points of connection - ALS: Think-Pair-Share .......................................79

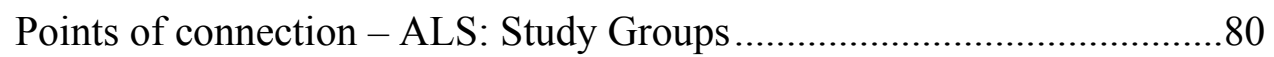

Points of resistance - CRP: Relatable Examples ........................................8

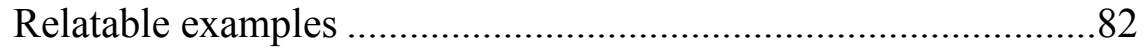

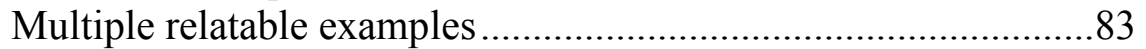

Points of resistance - Practice/Worksheet/Repetition ...............................84

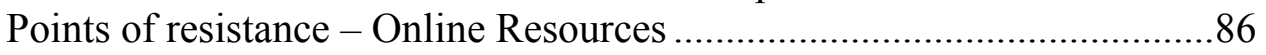

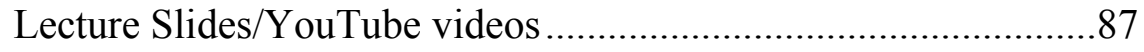

Study guide/practice test ............................................................. 88

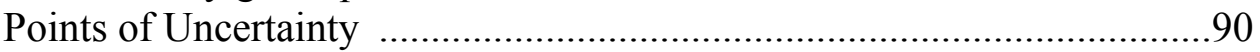

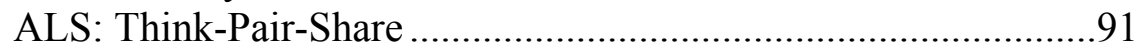


ALS: Group Study .......................................................................91

The overall outcome of CRP and ALS enhanced course ....................................92

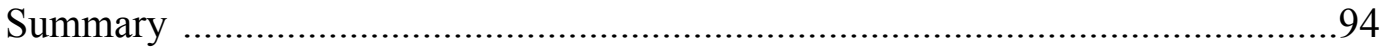

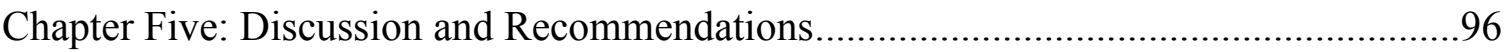

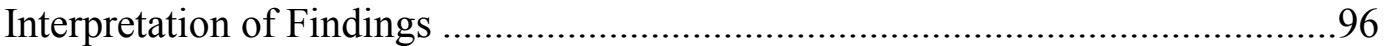

Implications in terms of Educational Leadership theory and practice...................99

Recommendation for unified CRP and ALS praxis.................................99

Implications for Instructor ................................................................101

Self-Reflection .....................................................................102

Need to develop all aspects of CRP ...............................104

Need to manage student resistance ………………..........105

Need to understand cultural diversity for AL .................106

Continuous Learning ....................................................................109

Implications in terms of Educational Policy issues ..........................................110

Professional Development (PD) ....................................................110

Faculty Contract ............................................................................111

Implications in terms of Education Equity issues................................................111

Change in instructional pedagogy to address diversity ...........................111

Increased class completion rates in STEM ...........................................112

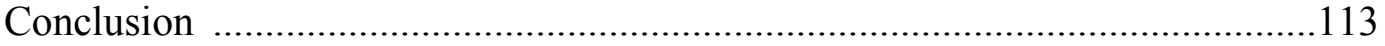

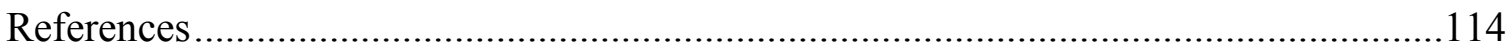

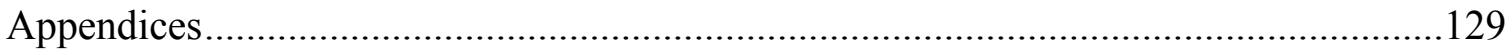




\section{LIST OF TABLES}

Table

Page

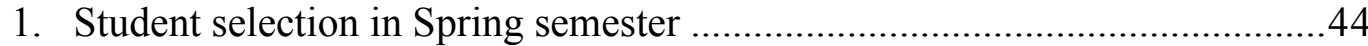

2. Student selection in Summer semester ........................................................45

3. Average Pass Rate in my classes......................................................... 92

4. Likert scale Data on Student Beliefs: Pretest vs. Posttest...............................94 


\section{LIST OF FIGURES}

Figure Page

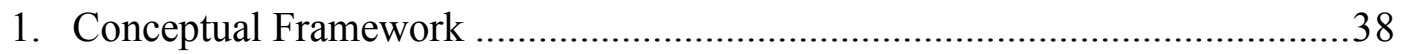




\section{LIST OF APPENDICES}

$\begin{array}{lll}\text { Appendix } & \text { Page }\end{array}$

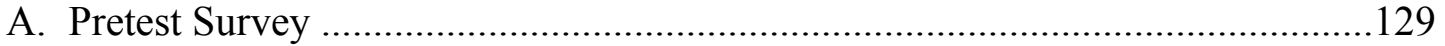

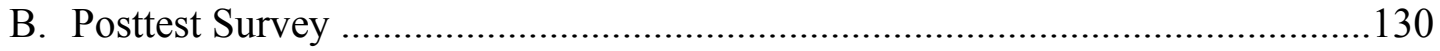

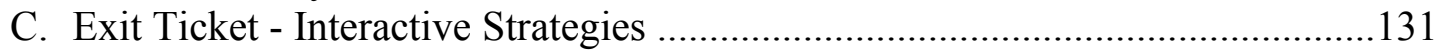

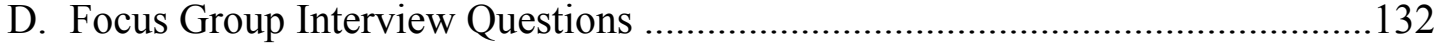

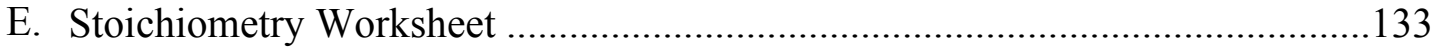




\section{Chapter One: Introduction}

When I first began teaching introductory chemistry at a community college (CC) in California fifteen years ago, I did not realize the extent to which my own prior educational experience impacted how I viewed my students, especially those who struggled in the class. My life as a student in my native country, India, was essentially stress-free. In my culture, the rich and working-class parents assume the responsibility to provide children with food and shelter, fund their education, and expect them to study and make a career. I belonged to that sub-group where my parents could afford my education, and I had no responsibilities at home other than studying. My teachers followed traditional teaching. In class, the students were supposed to be obedient, follow instructions, respect teachers, and did not question, since teachers perceived questioning as a challenge to their integrity. Based on my positive experience in the educational system in my childhood, I brought this image of "good schooling" and "being a good student" with me to the educational environment in the United States. After many years of teaching, I found out that student life is entirely different here in the United States, particularly at the community college level, and the definitions of "good schooling" and "being a good student" are different. My personal experience had influenced my professional experience, where a lack of understanding of student culture and American history negatively impacted my teaching practices.

My professional experience in the United States involved replicating my teachers' pedagogy, resulting in misconceptions about student cultures and their learning. As an instructor in a community college (CC), I anticipated that students' cultures, such as 
educational opportunities provided to them, are congruent everywhere. I assumed students in the United States in CCs had similar opportunities as those of students belonging to upper-middle-class families in my native country. My inaccurate perceptions of community college students in America resulted in blaming students for what I perceived as their failures. I was not taught American history when I was a student in my native country. As a novice community college instructor in America, I lacked the awareness of how colonialism in the United States contributed to the resultant inequitable learning opportunities provided to underserved students in high school. In my class, I treated students with a color-blind lens, as though the experiences they brought to the classroom did not matter as long as I taught information clearly, and they worked hard to ace the class. As far as my teaching style goes, I replicated the traditional teaching strategy of my teachers, whom I was taught to respect immensely. I focused on one-way lecturing, where I delivered the content, and I expected students to listen attentively. I would not allow students to have a conversation, come late to class, work on a lab during a lecture, or get distracted on the phone in the class. I believed I was doing an amazing job by keeping students focused and attentive during the lecture. While I accurately and diligently replicated the teaching style of my earlier professors, I failed to see the void it created in student learning.

The replication of teaching style based on the instructor's past experience leaves no room to grow pedagogically. I remembered that when I was a student, I used to have a lot of respect and admiration for professors who were knowledgeable about the content. With that memory engraved in my mind, I made sure I prepared my lectures well before I 
got to the class. At the beginning of my career, I used to spend many hours studying for my subject. I always felt that I had a complete command of my subject in my classroom. My delivery of the material was effective too. I was organized, and I cared deeply about students doing well. I used to intervene and talk to students individually if they were struggling and offered them help. I thought I was respectful to my students, and they seemed to be happy with me, as indicated by their comments. They came to me and talked to me personally to inform me that they appreciated my delivery of the lecture, my openness, and my approachability to them. However, I noticed that every semester, there was at least one student who was upset with me, and I could not figure out the reason. Looking back, I noticed that I was strict in a way that, to me, conveyed care and preparation but may not have been interpreted that way by some students. Since my lecture delivery was clear, I observed that students were attentive and took notes during my lecture. I also noticed they were quiet, even when I was not lecturing. I assumed it was a normal classroom environment, where students were well behaved in my perception until I evaluated my colleagues' classroom.

My perceptions of a normal class environment shifted after I evaluated my colleague's class. I noticed a classroom environment, where students seemed relaxed, which was different than my classroom. I saw their casual conversations with each other and their intermittent laughs. Also, I observed my colleague's way of interacting with students. She was a veteran instructor, and I was new to teaching. Since her office was next to mine, I could easily hear her conversations with students in her office. Later, I realized I was subconsciously dominating to my students. Students probably felt scared 
and were not comfortable, even if they appreciated my knowledge, organization, and caring demeanor. I learned from this experience that the faculty's knowledge of the subject is essential but not enough for student academic growth. Although I was working very hard to be an effective instructor, my interactions with students were missing. A welcoming classroom environment, where students can relax and do not fear the instructor, was lacking. I worked on changing my behavior, although it was not easy to change one's demeanor. My teaching experience inspired me to engage in self-study and action research.

This research stems from my experience of learning to be an effective chemistry professor. I teach Introductory Chemistry classes to students enrolled in Science, Technology, Engineering, and Mathematics (STEM) and Allied Health (AH) pathways in the Progress College in California. I started my teaching career with no specific training in teaching methods. I learned by evaluating my colleague's classrooms, by talking to veteran colleagues, by trial and error method, and by learning from my experiences. I used to wonder why some of my colleagues were not able to connect to students, despite teaching for many years. Now, I believe that they were struggling through the issues just like me at the start of my career. Some of those issues were a lack of awareness about student culture, the impact of a history of colonialization on underserved student populations, and how this system defines the faculty's role in supporting student learning. My extensive teaching experience and this doctoral program in the United States have contributed to further my professional growth. At present, I am better able to understand the inequities in education experienced by underserved students. 


\section{Research Scholar Experience}

In the Ed.D. program, I learned the history of coloniality in the United States of America and the rest of the world. According to So (1990), colonialization is the birthplace of the marginalized population. Coloniality creates discrimination in the form of racism (Quijano, 2007), where the institution is unable to recognize the struggles faced by underserved students, further causing harm to their academic growth. Instead, the college culture blames individuals for their failure to pass a STEM course, ignoring the institutional role in their general disenfranchisement. This lens of coloniality made me aware of the struggles of underserved students, particularly African American and Latin(x) students in a science classroom. Now, I acknowledge that their hardships in science classes are often the result of the inequitable education provided to them in their high schools, which is a by-product of colonialism. In the first semester of the doctoral program, I was convinced that I was a great instructor, and there was no reason for me to change or improve my pedagogical approach. Over time, and intentionally engaging with new ideas around educational equity, I identified a need to add-on to my pedagogy. That need was to advance to equity-focused teaching with student learning in mind.

While many of the ideas I have explored in my examination of practice are "known" in the research literature (Mesa et al., 2014), they are inconsistently and infrequently adopted, especially at the college level. The first-year chemistry class is a prerequisite for higher-level science and math courses at most community colleges as well as four-year colleges (Chen \& Soldner, 2014). Sadly, it has become a barrier to student success in the STEM pathway. According to Perez et al. (2014), 40\% of students, 
who declared STEM majors initially, switch to non-STEM majors. According to the authors, African American and Latin(x), students enter community college with aspirations to pass their prerequisites quickly so that they can enroll in higher-level courses. Unfortunately, they frequently end up withdrawing from the most challenging course, introductory chemistry (Lloyd \& Eckhardt, 2010). There is a need for self-study to explore equity-focused interactive pedagogical strategies and study their impact on student success, and document how a veteran instructor engages in this type of change. I believe my experiences with chemistry as a student, instructor, and now the doctoral candidate has guided my research in a self-study.

\section{Inequity in Community College STEM Outcomes}

Community colleges are the entry point for higher education. Community colleges (CCs) are designed to provide open access to all students, including underserved students, for higher education. They cater to students from poor socioeconomic status, and many students are immigrants and first-generation college students. In the academic year of 2016-2017, 6\% of African Americans and 44\% of Latin(x) students were enrolled in California's community college system (“California Community Colleges,” 2018). Lloyd and Eckhardt (2010) used data from the Government Accounting Office (Scott, 2008). The researchers found that many students, who enrolled in a community college instead of a four-year university, came from economically disadvantaged backgrounds where they did not receive equitable academic access while in high school, particularly for college preparation. It is the role of community colleges to prepare underserved 
students for STEM courses. Lloyd and Eckhardt (2010) argued the importance of community colleges offering STEM courses, in that almost half of the Bachelor of Science and Master of Science degrees in STEM were awarded to students who attended community college at some point in their lives.

The education provided in introductory-level STEM courses prepares students for the rigor and discipline required in higher-level learning. Introductory-level education can give students access to a broad range of living-wage careers and can open doors to higher wage STEM careers. Ultimately, introductory-level education increases the possibility of economic and social mobility. Our nation promotes STEM education to strengthen the United States in the global market to compete with fast-developing countries (Palmer et al., 2010). However, historically, African American and Latin(x) students have been strikingly underserved in STEM education and STEM careers (Goldfien \& Badway, 2014). According to Garcia (2010) and Adams et al. (2017), African American students are least likely to enter or complete STEM programs despite having comparable academic abilities as their White peers. Introductory Chemistry class is a prerequisite for higher-level classes in STEM and AH pathways, and as such, it is a gateway to STEM and AH careers. African American students were among the lowest group in the United States to earn an Associates' degree in Chemistry from 2010 to 2015 (NSF, n.d.).

\section{Inequitable college completion rates}

The overall completion rates based on ethnicity at two-year institutions in the U.S. are inequitable. In the academic year $2017-18,46 \%$ of White students in the United 
States were enrolled for credit in a total of 1,051 colleges compared to $25 \%$ of Latin(x) students and 13\% of African American students (AAAC 2019 Fact Sheet), which showed a systemic inequity among underserved students. Additionally, the 3 -year graduation rate was $23 \%$ for White students, $17 \%$ for Latin(x) students, but just $10 \%$ of African American students, the lowest among all ethnic groups for starting the cohort year 2011 (Musu-Gillette et al., 2017). The outcome remained unchanged from the previous cohort year 2010 (Musu-Gillette et al., 2016).

\section{Inequitable college completion rates in STEM}

The inequity in college completion rates based on ethnicity is particularly acute in STEM fields in the United States. African American and Latin(x) students have low retention rates in community college STEM courses. In 2014, only $12 \%$ of Associate degrees in science and engineering were awarded to African American, 19\% to Latin(x), and 50\% went to White students in 2014 (NSF, n.d.). Specific to Chemistry, only $0.03 \%$ of African Americans and $0.07 \%$ of Latin(x) students received Associates degrees in Chemistry in 2000 (NSF, n.d.). The trend did not improve with time. Only $0.02 \%$ of African Americans and $0.11 \%$ of Latin(x) students received Associates degrees in Chemistry in 2015 (NSF, n.d.). Like most other students, African American and Latin(x) students dream of graduating from community college and transferring to a four-year university. However, many underserved students frequently end up withdrawing from the most challenging course, introductory chemistry (Lloyd \& Eckhardt, 2010).

The disparity exists at my college as well. Progress College is a diverse institution in the heart of the San Francisco Bay Area. The success rates for all classes 
from Fall 2015 through 2017 are 65\% for Latin(x) students and 58\% for African American students, which is lower than the success rate of $76 \%$ for the White student body at Progress College. Progress College defines "success" when a student receives a grade of A, B, C, Credit, or Pass. The broader statistics signify a need to focus on the early success of students in science classes within STEM and Allied Health majors to promote equity, inclusion, and social justice.

\section{High attrition of underserved students in STEM}

There are many factors responsible for the high attrition of underserved students in a community college. One of the factors is Chemistry anxiety. Chemistry anxiety is a preconceived apprehension by students when they doubt their ability to learn and consequently to pass the course. This preconception can hurt student success rates (Widanski \& McCarthy, 2009). In a quantitative study, Widanski \& McCarthy concluded that Chemistry causes anxiety for many first-time science students in a twoyear college. An introductory math course is a prerequisite for the introductory chemistry course. Lack of math skills is another factor that contributes to student attrition in STEM. Researchers highlighted inequitable access to math courses for African American students and a lack of preparation for placement tests in high school as reasons for the challenges they face in community college (Adams et al., 2017).

Similarly, Samuel and Scott (2014) reported poor academic preparation as one of the barriers to the retention of Latin(x) students in community colleges. Weak interaction between instructors and students is one of the reasons for the academic preparation of underserved students (Spradley, 2001). When the instructor is unapproachable or asks 
intimidating questions, the students get demotivated, causing an impediment to their learning. Traditional lecture usually lacks student-instructor interactions since it is a oneway transfer of information from instructor to students (Lom, 2012). While the combination of factors, such as chemistry anxiety, lack of math skills, and inadequate academic preparation can hurt the retention rates of underserved students in STEM community college classes (Leopold \& Edgar, 2008), traditional pedagogy, and instructor's demeanor have also been recognized as significant factors in the high attrition of underserved students.

\section{Role of Faculty in Student Outcomes in STEM}

Though there are a variety of factors that contribute towards the disparity in outcomes discussed above, a key contributing factor is the persistent inequities within the P-12 education of many underserved students, that leaves them unprepared to pursue the academically rigorous course of study typified by STEM majors (Aldana, 2014). Not providing these students with the same educational opportunities as their peers who were provided advanced STEM-focused curriculum before entering college, puts underserved students at a stark disadvantage. Many of the underserved students on college campuses hail from low-performance high schools (Pitre, 2014) and, therefore, do not have equitable opportunities for foundation building in academic success (Darling-Hammond, 2015). Low-performing high schools may not be able to provide adequate resources for students, resulting in the unpreparedness of these students for college-level courses. Without awareness of and work to account for these differences in the academic 
experience, faculty members often blame students for their failure to pass challenging academic courses.

While students might have fewer opportunities to pursue rigorous STEM classes in high school, they bring potential strengths and knowledge to the classroom (Yosso, 2005). For instance, many students bring with them caring, supporting values, and a sense of community to the classroom. When faculty members have perceptions that incoming students must already have strong study skills and be scientifically literate to be successful in higher education, and fail to build upon the inherent strengths that the student presents with if they don't align with these preconceived notions of success, it impedes the educational and career goals of many underserved students. When the instructor fails to build upon the student's strength, the instructor is likely to see the differences as deficits (Benham, 2007). Studies have shown that the attitude of an instructor that places blame on the student for failure to learn the material, diminishes the student-teacher relationship, and negatively affects the students' academic outcomes (Benham, 2007; Hill, 2009).

The unwelcoming demeanor of the instructor contributes to the low success rates of underserved students. Rocca (2010) reviewed the literature on in-class student participation within community colleges and universities, dated from 1958 to 2009 . The researcher concluded that students begin to feel anxious and defensive when an instructor displays an unwelcoming demeanor. The instructor's attitude is considered unwelcome when the instructor shows aggressive conduct, sarcasm, or an authoritative position. Some instructors hold stereotypical beliefs against minoritized students, which 
also shows up within their interactions with such students, resulting in a negative relationship between such faculty members and their students (Seglem \& Garcia, 2015). African American students, in particular, reported having experienced explicit discrimination by White faculty members through the assumption that Black students are not "smart enough" (Malcom et al., 2016). Allowing these stereotypical beliefs to infiltrate classrooms takes away a students' sense of belonging and contributes towards the high attrition rate among minoritized students (Strayhorn, 2015).

The traditional pedagogical approaches, such as exclusively teaching through lectures and exerting an authoritative demeanor within the classroom, have been ineffective towards adequately supporting underserved student populations (Watkins \& Mazur, 2013). An authoritarian demeanor is a top-down transactional attitude, where everyone is required to accept the authority of the instructor "as-is." Watkins and Mazur (2013), in their quantitative research study, found that approximately twice the amount of students enrolled in a traditional physics course left the STEM pathway over time. The unwelcoming demeanor of instructors and traditional teaching styles were noted as factors contributing to low success rates of underserved students. There is a great need for understanding the teaching strategies and the role of faculty in the classroom to support student learning within first-year STEM courses in particular as this time frame serves as a pivotal point to improve the retention rates of STEM students.

The role of faculty is to support students by embracing their diversity and promoting their participation in class. Only when faculty members discard a deficitbased view of students, they will be able to form a bond with them through recognizing 
the importance of cultivating positive social interactions, and allowing students to feel seen and included (Pitre, 2014). Engaging teaching strategies, such as providing instant feedback, promoting collaborative learning, and being receptive to questions, demonstrate an increase in student retention in a STEM major (Watkins \& Mazur, 2013). Ladson-Billings (1995) defines culturally responsive pedagogy (CRP) as teaching practices, where the instructor takes responsibility for student success and supports students in developing cultural competence and critical consciousness. A culturally responsive instructor connects abstract content to students' familiar experiences, promotes critical thinking through collaborative work, provides instant feedback, and has high expectations (Aceves \& Orosco, 2014). Seglem and Garcia (2015) concluded that when teachers were given professional training to include student-centered activities in class, it resulted in student engagement.

When CRP is in place as a foundation, we can cultivate spaces of active learning that will further contribute to a student's successful acquisition of the material. Active learning consists of strategies that are student-centered activities, where students actively seek new information while working in collaboration with peers (Allen and Tanner, 2005). Scholars Talanquer and Pollard (2017) highlighted the importance of utilizing active learning within classroom spaces. These researchers revised the curriculum of their general chemistry courses to incorporate active learning and promote what they called "chemical thinking." The researchers defined chemical thinking as engaging students in analyzing, developing, and applying the concepts to diverse contexts. The researchers used a collaborative learning space to divide a large class of 264 students into 
groups of six students each. The researchers found that the chemical thinking curriculum resulted in an increase in average grades on the American Chemical Society (ACS) conceptual exams for underserved groups. Although African American and Latinx students' scores increased by $2 \%$ (from $61 \%$ to $63 \%$ ), there was a statistically significant decrease of $8 \%$ (from $53 \%$ to $41 \%$ ) in the average failure rates for these two student groups. Other scholars such as Boda and Weiser (2018) have also replicated these findings to show that active learning strategies that include student collaboration and engagement are highly effective for students in remedial chemistry courses in comparison to traditional styles of teaching. Active learning in STEM at a community college level, therefore, appears to have a positive impact on student success (Freeman et al., 2014). Active learning results in community building within classrooms, as it increases student motivation, and contributes towards their persistence in STEM majors. Auerback and Andrews (2018) posited that instructors who implement active learning practices create opportunities for cultivating safe spaces for students to engage with teachers and their peers. These safe environments help stimulate students' critical thinking processes. To conclude, active learning, embedded within a culturally responsive pedagogy framework, actively engages students within the classroom. Therefore, we must improve the pedagogy and awareness among instructors to create an inclusive environment for all students. This paper examines how my teaching is changing to better meet students' needs in a STEM classroom. 


\section{Impact of Pedagogical Stance on STEM Learning}

My goal is to help increase student success in an introductory chemistry course at a community college by creating a more interactive classroom environment. As discussed above, in my novice years as an instructor, I thought that I was doing a good job by successfully delivering the content to all students, and I could conveniently blame them for their poor self-efficacy in cases where they failed. However, the successful delivery of a lecture is not enough to help underserved students persist. A traditional lecture pedagogy excludes many underserved students from learning because it is a oneway, top-down instructional strategy, where the instructor is considered supreme (Zeichner, 2002). On the other hand, student-centered learning is an alternative instructional strategy that has proven to be effective (Lloyd \& Eckhardt, 2010). Instructors, who embrace culturally responsive pedagogy (CRP), utilize interactive and collaborative approaches to support student learning (Aceves \& Orosco, 2014).

Most studies around the positive impact of culturally responsive pedagogy on underserved STEM students in community colleges focus primarily on biology (e.g., Palmer et al., 2011; Graham et al., 2013; Strayhorm, 2015). I found a dearth of similar research in chemistry. That's where my research will be productive. It may confirm the existing studies and add nuance to a field of chemistry. My research study and the questions will help me modify my teaching, and I will recommend self-study for faculty for self-examination, necessary for educational reform. 


\section{The problem of Practice and Research Questions}

My problem of practice is to explore a cluster of instructional strategies to promote student achievement in the first-year community college chemistry course. I am interested in introductory chemistry class in the Allied Health pathway since, as discussed above, this pathway currently provides access to STEM careers for many underserved students.

The following questions guide my methodology:

1. How does facilitating interactive pedagogy impact students' experience in a firstyear chemistry class for AH students?

2. How does focusing on culturally responsive practices change my stance as a chemistry professor?

\section{Educational Leadership}

It is the mission of Progress College to bring equity, inclusion, and social justice to the educational system. The instructional leadership of the college tends to have a shared vision and a shared commitment to bring change. However, the introductory chemistry class in the Allied Health pathway remains a gatekeeper science course. There is a strong need to support students in gatekeeper science courses, particularly students in AH and similar fields that provide pathways to the higher-level courses. The high failure rate in the introductory chemistry points to a gap between the college's mission and student outcomes. 
There is a need to address a lack of equity-based professional development, to dismantle deficit views and negative profiling of underserved students. We need to find ways to increase commitment to teaching in inclusive and affirming ways. Even though professional training is mandatory for $\mathrm{CC}$ instructors, it does not address self-study to examine our teaching practices to bring change. The purpose of this self-study is to explore an active learning strategy within the framework of culturally responsive pedagogy to impact student outcomes positively. Therefore, my teacher research has the potential for leadership to encourage self-study to bring systemic change to my college. Until then, underserved students remain isolated and disengaged, which remains a barrier to students' academic achievement in science.

The findings from this self-study will inform me of the impact of instructional strategies on student achievement in the introductory science course. According to Megowan-Romanowicz, 2010, teacher research results in transforming pedagogy such that it changes the way the teachers think about student learning. Therefore, teachers start paying attention to things that they previously used to overlook. I will share the findings from this self-study with the faculty in science and math departments so that we have a shared vision and commitment to bring a change in the educational outcome of underserved students. The implication of self-study is to involve the organization in the pedagogical reforms at the institution level, which can be accomplished by promoting self-study, forming professional learning communities, and collaborating to support student learning (Fulton \& Britton, 2011). This study is vital for educational leadership since it is the moral responsibility of faculty to design instructional strategies and self- 
examine through self-study to help underserved student academic outcomes in introductory STEM and Allied Health courses in a community college. 


\section{Chapter Two: Literature Review}

This research study will explore culturally responsive practices (CRP), active learning strategies (ALS), and my reflections on my teaching approach through self-study in my attempt to engage my students in my introductory chemistry course in the Progress College. Culturally responsive practices and active learning strategies have been identified to support equity, social justice, and inclusion in large introductory STEM classes. In this section, I will introduce self-study, CRP, and ALS.

Self-Study. Self-study for a teacher is a way of examining self by unpacking personal experiences and transforming professional identity to find a deeper meaning of the practice of teaching (Loughran, 2005). There is an ambient need for teacher educators to look into their own lived experiences and their impact on pedagogical practices. Selfstudy is an essential resource for professional development, and as such, it is an instrument in bringing educational reform. Self-study is a pedagogical strategy that serves as a meaning-making event, which can facilitate the transformation of teaching and learning (Chan, 2012).

Culturally Responsive Practices (CRP). Culturally Responsive Practices have been used in various academic settings to help counter traditional and inequitable ways of instruction. Here, the instructor acknowledges students' diverse backgrounds and utilizes student knowledge and culture to augment the lesson plan instead of treating it as a barrier (Nieto \& Irizarry, 2012). Jackson (1993) recommends that building trust, using effective questioning techniques, and providing useful feedback are some of the strategies to support CRP. It involves believing that all students can learn to engage. The 
instructor and students form a communal environment where students are responsible for each other in learning instead of participating in mutual competition (Ladson-Billings, 1995). The instructor is caring, promotes dialogue with students, and facilitates their mutual interactions.

Active Learning Strategies (ALS). Active learning strategies consist of a short course-related paired or small group activities in which every student is participating, processing the knowledge, and synthesizing new information (Felder \& Brent, 2009). All students learn actively in group study by sharing their ideas, helping to solve problems, and discussing intellectually to reach an agreement and work towards a common goal (Johnson \& Johnson, 2008). Active learning occurs when students can think about the concept, associate it with relatable examples, and discuss with peers. It results in enhanced student participation in class, which in turn promotes their academic achievement.

\section{Review of Literature}

In this section, I will look at evidence related to self-study, culturally responsive pedagogy, and active learning strategies. This literature review will analyze current practices to illustrate the strength of CRP and ALS by themselves. Specifically, selfstudy research has explored the benefits of improving teaching practices in STEM classrooms. Many self-studies are not grounded in the literature of CRP and ALS as a joint component. This self-study will focus on the collective impact of CRP and ALS on student learning in the introductory chemistry classroom in a community college. First, I 
will explain Self-Study, and then I will discuss CRP, followed by ALS, which will lay a foundation for my research. I will use the explanation of CRP and ALS to support the evidence that ALS is a required component of CRP for student academic achievement. Self-Study

Self-study is teacher research, where the teachers reflect on their own teaching practices. Dewey (1933) claimed that self-study involves reflective thinking. It is a mode of teacher research to do a self-examination to grow in teaching. Self-study provides an entry point to a life-long learning process, which is vital for teachers' professional development. However, there is a dearth of literature specific to self-study in STEM in a community college program (Murphy, 2016). That's where my research will be adding value to the literature.

Self-study is a process to unveil essential aspects of knowledge about our teaching practices. Teaching practices are embedded in personal experiences and relationships. Self-study leads to a newfound understanding of the intricate relationship between learning, teaching, and lived experiences (Chen, 2012). In the process of selfstudy, teacher educators start to capture, unpack, and characterize the complexities of teaching, leading to a deeper understanding of practice (Loughran, 2005). My intense self-evaluation will give me an in-depth understanding of the tangled relationship between life, learning, and teaching. Through self-study, I will examine my lived experiences and its effect on my teaching practices. I will step back and draw inferences and lessons from my experiences. Self-study involves the use of reflective inquiry. My self-study might reflect a change in my self-identity. 
The purpose of self-study is two-fold. One is to engage in a study for personal and professional development. The other is to understand teacher education practices, processes, and contexts. Self-study includes the self-examination of pedagogical practices and causes the educator to be more reflective of the teaching choices they make. Self-study has the potential to bring change to the teaching practices utilized within science classrooms in community colleges because critical self-reflection will help the educator better ascertain what is working and what is not. Despite these inherent benefits, self-study comes with tension since it is up close and personal (Powell, 2012). It makes the researcher susceptible to public scrutiny, especially once the selfstudy is publicized (Loughran, 2007).

A pedagogical change is necessary to enhance student engagement and steer towards more in-depth learning. Teacher educators, who engage in self-study, are committed to teaching and bringing educational reform. (Cole \& Knowles, 2005). Selfstudy has a reformative purpose. It provides an opportunity to peek at personal history, which is essential in reforming teaching practices and, as a result, transforming the educational experiences of students (Samaras et al., 2004). I have become an active agent of my learning. By sharing my lived experiences and their impact on my teaching experiences, I hope it will refine my teaching practice and help others in their pedagogical approaches.

\section{Culturally Responsive Practices (CRP)}

A culturally responsive pedagogy involves instructor qualities, use of relatable examples, and instructor efforts in building a classroom structure that is conducive to 
learning. A culturally responsive instructor is caring, accessible to students, and shares power with them in a classroom (Ladson-Billings, 1995). The instructor caters to student needs by connecting prior information to new knowledge. The instructor is respectful to students, interactive, and receptive to their questions. The instructor makes the classroom environment welcoming and promotes collaborating learning, where students learn by supporting each other (Gay, 2002). It is in direct contrast to traditional pedagogy, which is monologic, where instructor lectures in class to deliver information, and students take this information and treat it as auspicious without questioning it. Now I will discuss instructor qualities, use of relatable examples, and classroom structure/community building aspects of CRP in detail. However, these studies lack the component of Active Learning and its effect on student learning.

\section{Instructor Qualities}

Caring and approachable. A caring and respectful demeanor of the instructor is a component of culturally responsive practices. It endorses a sense of belonging to the classroom. Students start to value themselves and try their best to succeed. The traditional pedagogy does not include faculty-student interaction. Therefore, it results in shallow learning, such as transferring all the information received from an instructor to a piece of paper during an exam (Gay, 2002). In contrast, when instructors make personalized time for students, it shows that they care for their students.

Scholars have studied the impact on instructor demeanor on student persistence. Witt et al. (2014) quoted in their study, "when students perceive instructors as competent, trustworthy, and caring individuals, students' internal attitudes and 
performance levels are enhanced" (p. 336). In their quantitative analysis, the researchers showed a $13 \%$ positive statistically significant correlation between the instructor's credibility and student intent to persist. The authors emphasized the positive impact of instructor demeanor on student persistence. They illustrated the importance of instructors requiring a positive attitude and supporting students with their individual needs, which supports the conceptual model of culturally responsive pedagogy.

CRP is a student-centered approach where the instructor cares about students and believes that every student can learn and is capable of academic success. Ladson-Billings (1995) argues that a caring instructor develops a feeling of a greater sense of commitment. The instructor respects students and encourages them to be themselves as they engage in class discussions. Therefore, it leads to an excellent student-instructor relationship. Students exposed to CRP perform better than their counterparts, and instructors feel that it is their responsibility to help students succeed academically (Ladson-Billings, 1995; Morrison et al., 2008). Instructors care about students and make themselves available to them. It facilitates student success and self-esteem (Gay, 2002).

Promotes reasoning. According to Ladson-Billings (1995), teachers must be passionate about knowledge and learning. The experience is not static and does not come from one direction only. The author clarifies the students' right-answer approach. The instructor makes it clear to students that there is a difference between an intellectual challenge and a challenge to a higher authority. Students need to think logically about why the answer is right and not because the instructor said so. 
Power sharing. CRP involves a student-centered instruction approach where the instructor responds to student needs, encourages their participation in class, and allows them to make essential classroom decisions. According to Morrison et al. (2008), a culturally responsive instructor treats students as equals and therefore shares power with them. The instructor is flexible in class and provides opportunities for students to decide classroom activities and assist them as they engage in their actions (Aceves \& Orosco, 2014). Instructors who frequently draw upon student interest in creating classroom activities demonstrate a culturally responsive classroom structure.

Examples, demos, connect prior information to new knowledge. According to Gay (2002), in a culturally responsive classroom, a high percentage of instructional time is used in giving examples and scenarios to demonstrate information and concepts, which are pedagogical bridges to connect prior information to the new knowledge. Instructional scaffolding practice occurs when an instructor genuinely cares about student understanding of the concept, acknowledges student needs, and provides supporting material to meet their needs (Aceves \& Orosco, 2014). The instructor models learning by providing examples based on familiar experiences and relating observations to the abstract content (Aceves \& Orosco, 2014). It stimulates students thinking as they start connecting the content to their familiar experiences.

Interactive. When an instructor is interacting with students in a classroom, it results in their higher academic success. Hurtado et al. (2011) did a mixed-method study on student interaction with faculty and its impact on their success. The authors concluded that African American students in STEM have better success rates when they 
have frequent interactions with faculty. However, the authors did not study the application of relatable examples or ALS to help the student engage.

Similarly, Kezar and Maxey (2014) demonstrated a positive impact of the caring demeanor and faculty-student interactions on student success. The authors posit that when the underserved students experience caring instructors, they feel a sense of belonging, they strengthen their interactions with faculty, they build a community, and thereby student persistence in STEM increases. The researchers reinforced the findings of Hurtado et al. (2011) study that faculty-student interactions have a positive effect on the persistence of African American and Latin(x) students towards degree completion. The interactive instructors create opportune moments to connect with students personally and offer individualized support. When the instructors are openminded, demonstrate their availability, and are responsive to student needs, it enhances the instructor-student relationship.

Receptive to questions. Responsive feedback practice is when the instructor is receptive to student questions and encourages students to ask questions (Ladson-Billings, 1995). The instructor being receptive to student questions has a two-fold purpose. The instructor can monitor student understanding through responsive feedback practice, whereas ongoing feedback increases student self-esteem and their understanding of the material (Aceves \& Orosco, 2014). All these studies, showing the impact of CRP on student engagement, are independent of active learning strategies.

Relatable examples. Another CRP approach is when an instructor provides materials, which may not be in the curriculum, but they support student 
learning. Relatable examples are the ones that instructors continuously make connections to students' everyday experiences for them to experience academic achievement (Aceves \& Orosco, 2014). Instructors reconstruct the content with examples with their own acquired knowledge and insights and scaffold student familiar experiences in their lesson plans (Gay, 2002). Willingham (2003) recommended that teachers must design classroom activities and assignments in a way that promotes student thought processes. It would result in students' more profound understanding of the concept. However, he did not research active learning strategies. According to Morrison et al. (2008), the instructor goes beyond the prescribed curriculum and includes students, their familiar experiences, and relatable examples to connect to the content. All these studies, showing the impact of CRP on student engagement, are independent of active learning strategies.

Classroom structures/community building. A culturally responsive instructor builds a nurturing classroom environment, promotes collaborative learning, recognizes student excellence, and provides resources to students to support their learning.

Classroom Environment. A CRP includes an environment that is conducive to student learning. According to Morrison et al. (2008), instructors support students in meeting their academic expectations by creating a nurturing and cooperative environment where students feel motivated to work to the best of their abilities. The instructor creates equity in class and engages students in activities to increase their sense of belonging. A culturally responsive instructor fosters interaction that creates a sense of belonging.

When a classroom environment is safe and welcoming, students feel a sense of belonging, which is required to improve student retention (O'Keeffe, 2013). Mesa et al. 
(2014) concluded that an excellent instructor-student interaction is a foundation of a welcoming environment in the class, which promotes student engagement. In their qualitative analysis, Godwin and Potvin (2017) stressed the importance of setting up a classroom environment that invites students to make comments and participate voluntarily without any fear of repercussions.

Ladson-Billings (1995) emphasized that when an instructor promotes interactions with students in the class, it results in establishing a community, where the instructor becomes a part of the student community. In such an environment, students respect each other and feel free to critique the content, which results in their academic growth. In summary, a classroom environment is inviting when the instructor provides a safe place for students to engage in activities, trust each other, and build a community to support each other in learning.

Collaborative Learning. When students work in collaboration with peers in a large classroom, they constitute a community of learners. The authors claim that the fostering community motivates students to think critically to seek deeper learning. Students begin to see themselves as a part of the community, and therefore, they feel welcomed and valued. According to Ladson-Billings (1995), culturally responsive instructors encourage students to work in collaboration and support each other in learning by taking responsibility for each other's success. It increases communication among students, which is not didactic in that one person is talking, and others are listening. Instead, it is active and participatory so that all peers are contributing to the discussion (Gay, 2002). The researcher posits that the reason for better skills acquisition 
is that the students are encouraged to work as a community and support each other in their learning.

The instructor builds communities among diverse learners for their collaborative learning. Instructors consciously create social interactions to lead students to academic excellence, encourage them to learn collaboratively, and be responsible for each other instead of opting for individual competitive achievement. When students work in collaboration, everyone contributes individually and takes responsibility for group success. If a group fails or succeeds, it affects personal progress.

Recognizing a student's strength. A culturally responsive instructor highlights the expertise of various students and requires struggling students to consult with these students with knowledge before coming to him/her for assistance. It makes students aware that they are expected to excel at something, and they will be called to share their expertise with peers (Ladson-Billings, 1995). All these studies showing the impact of CRP on student engagement are independent of active learning strategies.

Now, I have explained the studies exclusively on CRP and its impact on student learning. Now I will transition to active learning strategies (ALS) and their effects on student achievement. After that, I will build a case that CRP and ALS in STEM are not mutually exclusive in supporting student learning. Instead, ALS is an essential component of CRP to increase student academic achievement.

\section{Active Learning Strategies (ALS)}

Active learning strategies involve students in constructing knowledge actively with increased student-to-instructor interactions and student-to-student interactions in the 
classroom (Auerbach \& Andrews, 2018). In ALS, students question knowledge and explore with a peer using a think-pair-share strategy or work in small groups. They are not passive listeners, as in traditional pedagogy. Now I will share in detail about some key aspects of ALS, such as group study and think-pair-share.

Group Study. Researchers have examined how classroom climate can intentionally be developed to include and support an underserved student population rather than exclude them (Freeman et al., 2014). A group study involves participation in STEM-related activities as a group activity in a way that each student actively synthesizes the information. Small group study promotes a culture of collaboration, where students can participate and work together in classroom activities or discussions. Scholars have used this small group study in various settings in the math and science departments in community colleges.

According to Bonet and Walters (2016), a small group study has a positive impact on student learning. The authors quantitatively analyzed the short-term effects of using four Learning Communities and four Regular Sections in a community college. Learning communities consisted of small class sizes, and students were required to enroll in weekly tutoring sessions. The authors found that the overall grade point average in the learning communities was half a grade higher than that in regular sections. The grade distribution showed that more students got an A grade, and fewer students failed the class. The percent of students getting B through D grades was not significantly affected. To me, it is not clear if the increase in the higher passing rate in LC students is due to small class size or incorporation of tutoring sessions. 
Both small class sizes and tutoring involves group work resulting in enhanced interactions (Bonet \& Walters, 2016). While working in groups, the students critically evaluate their prior understandings of academic realities for deeper learning. Studying and learning together helps students combat their academic challenges and provides a positive social network. While the authors did not examine the impact of instructor demeanor or relatable examples on student learning, they did prove that working in small groups motivates students and therefore positively impacts student retention.

Palmer et al. (2011) explored the factors responsible for the retention and persistence of underserved students in STEM. In their qualitative research, the researchers interviewed students for 90-110 minutes and followed up with telephone interviews. Students constructed knowledge and understanding through meaningful interactions. The researchers audiotaped and transcribed all interviews. After coding the data using grounded theory, the researchers found that peer support groups had a positive impact on students' success as they fostered a safe and welcoming classroom climate. Similarly, Rissanen (2018) showed that student grades improved when they were given opportunities in a large Biology classroom to engage in critical thinking. In both studies, working in groups towards problem-solving increases student collaboration and engagement.

Think-Pair-Share (TPS). The Think-Pair-Share strategy is a student-centered learning approach, which allows the instructor to set time aside for students to think quietly about the assigned problem. After having the opportunity to personally think about the problem or content taught, students pair up and share the ideas or solutions with 
their partners. The group then shares responses with the class, followed by the instructor's explanation in the end (Felder \& Brent, 2009; Brame \& Director, 2016). Such activities allow students to participate actively in constructing new knowledge. Student collaboration is critical because students work towards shared goals, and they meet academic challenges collectively (Zepke \& Leach, 2010). In contrast, a traditional lecture is an instructor-centered activity where students receive the information passively, resulting in ineffectiveness in their learning (Lom, 2012). It is clear across these studies that the TPS strategy, a student-centered activity, is effective teaching strategy (LoPresto \& Slater, 2016).

Bataineh (2015) found similar results in a quantitative study where he compared academic outcomes using traditional teaching with those with TPS strategy in psychology, special education, and Islamic studies. The author found that the students in the TPS groups had statistically significantly higher scores than those in traditional teaching. However, the extent of benefits is not clear from this study, which is why my research will be beneficial. Bataineh (2015) suggests that the TPS strategy is not restricted to specific majors; it can be applied to all STEM majors.

Bamiro (2015) used a quantitative approach to study the effects of TPS strategies on secondary school student achievement in chemistry. The researcher concluded that the use of these student-centered strategies resulted in their improved academic performance, cognitive skills, problem-solving skills, and better learning in Chemistry. The authors found that there was a $20 \%$ increase in adjusted mean achievement scores with student-centered strategies, such as TPS, compared to traditional 
lectures- In their mixed-method study of the impact of TPS strategy on student engagement in a computer science course, Kothiyal et al. (2013) found that an average of $83 \%$ of the class remained engaged throughout the semester. It shows that the TPS strategy increases student engagement in STEM majors. All these studies show that students learn actively in a class by constructing new knowledge by collaborating with peers. However, these studies lack a component of CRP, where the instructor's demeanor creates a good classroom environment, and the instructor promotes learning by connecting to student familiar experiences (Ladson-Billings, 1995).

Tanner (2013) recommended twenty-one strategies to promote engagement, inclusion, and equity in a large Biology classroom. Some of the strategies include wait time, writing time, TPS as a classroom activity, worksheet, a project as outside the class activity. The author recommended that an instructor must encourage students to work in small groups using active-learning approaches. The author stressed the importance of providing students time to think, followed by an in-class discussion about science concepts. The purpose of the study is to uncover how an instructor can engage all students in the class using ALS. Although the author did not mention CRP in her study, this paper does address certain aspects of CRP. For example, some of the strategies discussed by the author, such as monitoring student participation, integrating culturally diverse and relevant examples, and be explicit about promoting access and equity for all students are the components of CRP (Ladson-Billings, 1995). 


\section{Summary}

The goal of the literature review was to examine teacher research, explore the impact of culturally responsive practices (CRP) and active learning strategies (ALS), and how the effects of ALS in combination with CRP shapes student engagement in STEM classrooms. The literature revealed that underserved students, especially African American and Latin(x) struggle in the introductory STEM courses, and many leave the STEM field in their first year of college, which is mainly due to the traditional pedagogy used in the classrooms. The reviewed studies have provided insight into certain practices of both CRP and ALS that can be effective in promoting student engagement in the STEM classroom. There are specific components of CRP which are not active learning (ALS) and vice versa. However, I am arguing that ALS is a necessary component of CRP to enhance student engagement and academic success.

The theoretical framework of culturally responsive pedagogy involves culturally responsive practices (CRP) in combination with active learning strategies (ALS). Culturally responsive practices endorse a caring instructor, who provides a safe environment, shares the classroom equally with students, and supports their learning in collaboration. A safe classroom environment is not an active learning strategy, but it is required for active learning where students are motivated to engage in activities for more in-depth learning. Active learning culminates in enhanced student engagement, peer interaction, faculty-student interaction, and critical thinking. When students are learning actively by working together in small groups or using TPS strategy, they think logically and build new knowledge. Active learning strategies cannot be enforced if the instructor 
does not create a nurturing classroom environment. Active learning cannot be productive if students are competing instead of being responsible for each other's success.

After a thorough review of the literature, I would like to gain a better understanding of how my teaching approach of active learning strategies scaffolded into culturally responsive practices impacts student achievement in my large STEM classroom in a community college. I will conduct a self-study and explore my teaching practices, in which active learning strategies will be implemented along with culturally responsive practices. The following questions guide my methodology:

1. How does facilitating interactive pedagogy impact students' experience in a firstyear chemistry class for AH students?

2. How does focusing on culturally responsive practices change my stance as a chemistry professor?

I will examine my daily lived experiences and their impact on my teaching and student learning. I am interested in giving voices to students in finding out the impact of active learning in a culturally responsive environment on their engagement. My selfstudy can show that a CRP is required to implement ALS in introductory chemistry class in a community college to improve student engagement. My research can guide future researchers to examine self, explore the effect of various pedagogical practices in a theoretical framework of culturally responsive pedagogy on student achievement. 


\section{Chapter Three: Methodology}

This research project is a self-study that explored the combination of interactive strategies intended to promote student achievement in a first-year community college chemistry class. Self-study is a tool to examine and reflect on personal teaching practices to make teaching more effective and meaningful (Chan, 2012). I hope that studying the impact of different strategies in my class will help me to identify and further develop a promising strategy to increase outcomes, especially for students from groups underserved in STEM and Allied Health.

This study explored a combination of interactive strategies that I analyzed in terms of their impact on student achievement in my first-year chemistry class. I designed my data collection and analysis techniques to prioritize student voice and stance in analyzing effectiveness. While outcome data were readily available in the form of institutional research databases, student voice regarding their own experience was often missing from more extensive data sets. The more intimate setting of self-study allowed me to prioritize the voices of my students, thus provided insight into adequate supports for students in my classes. To me, student voices are authentic, raw, and meaningful. Because there might be perceived risk in critiquing of a class in which students were enrolled, some of the data was in the form of anonymous pretest surveys, anonymous exit-tickets, and anonymous posttest surveys so that students were free to write their views without any fear of being identified and penalized for their voices. I compared the students' pass rate in my classes within different semesters. The five perspectives pretest survey, exit tickets, interviews, posttest survey, pass rates - provided a multi- 
layered understanding of how students took up the strategies under investigation. I took field notes to reflect on my experiences as an instructor and as a participant. Based on the findings, I am interested in improving my instructional pedagogy to enhance underserved student achievement in introductory science courses. I will share the findings of my study with STEM and Allied Health (AH) faculty in my college and other community colleges as a step toward improving STEM learning more broadly.

\section{The problem of Practice and Research Questions}

My research problem is to explore a cluster of instructional strategies intended to promote student achievement in the first-year community college chemistry course. The analysis of the impact will focus on underserved student populations, primarily African American and Latin(x) students. The following questions guided my methodology:

1. How does facilitating interactive pedagogy impact students' experience in a firstyear chemistry class for AH students?

2. How does focusing on culturally responsive practices change my stance as a chemistry professor?

\section{Conceptual Framework}

In this study, I anticipated that the adoption of practices informed by culturally responsive pedagogy (CRP) would increase Allied Health students' achievement in the first-year STEM community college course. In this self-study, I focused primarily on strategies to increase students' connection to chemistry content and facilitated social/peer 
support for learning. Through a cycle of iterative refinement (see figure 1), I evaluated the effectiveness of my pedagogical shifts and made further changes based on student feedback and outcome data.

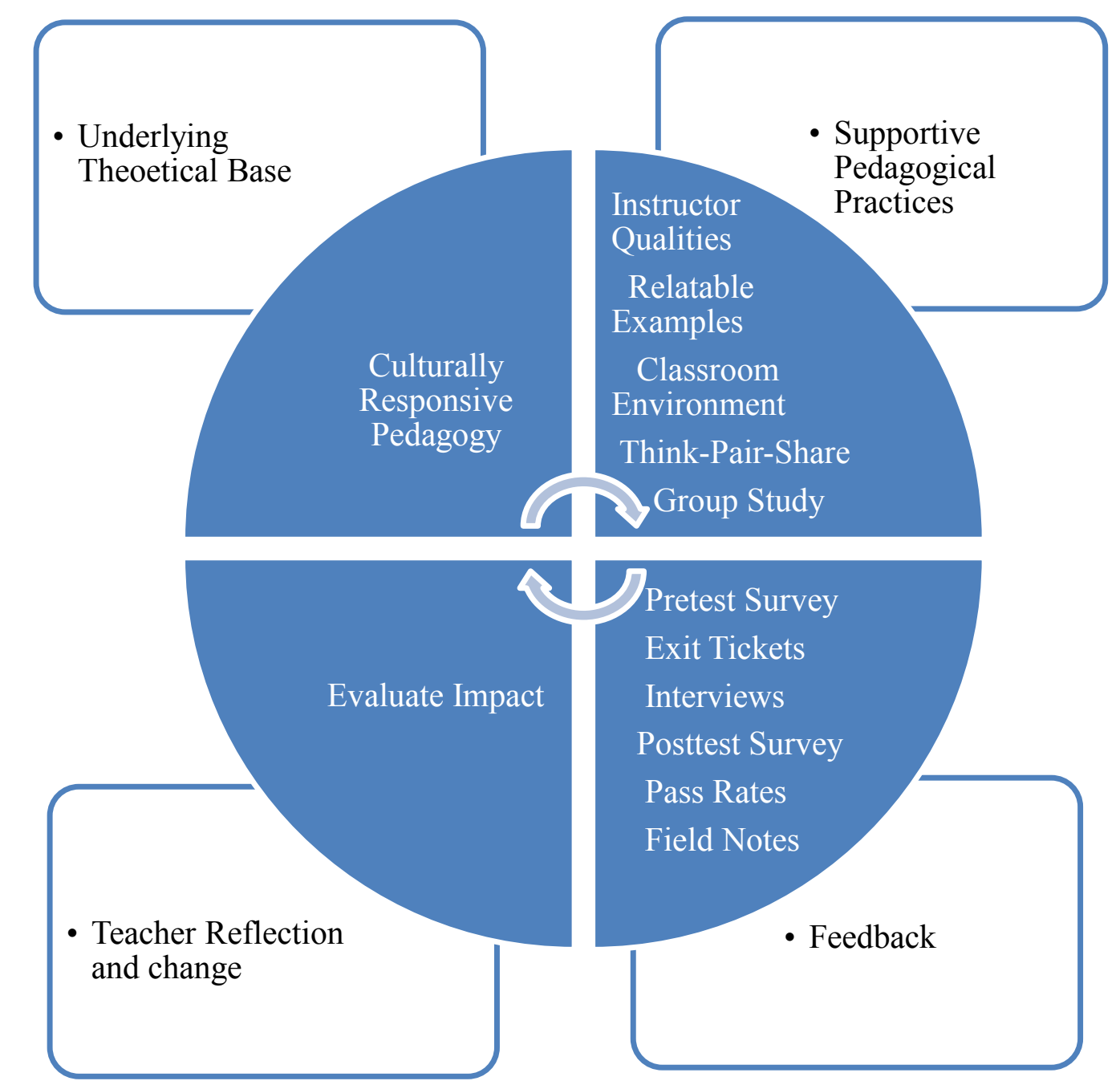

Figure 1. Conceptual Framework 
The culturally responsive framework is a continual cycle of applying supportive pedagogical practices, seeking feedback, and analyzing their impact on student learning. It is an iterative process of the teacher research cycle with ongoing improvement in pedagogical practices. The process of trying active learning in introductory science classes is not a one-time process. It is essential to keep in mind that after my dissertation, I will continue to work on various strategies, looking for feedback, and improving my pedagogy to promote student academic learning. There is never a perfect scenario. We must keep evolving to seek better results. Culturally responsive pedagogy is not only a part of active learning, but it is also embedded in every section of the process. In the picture (see figure 1), I placed it as a separate section because of a continual need to return to it.

\section{Site and Participant Selection}

This study took place in my introductory chemistry class at Progress College in 2019. It is a community college in California with a diverse population of approximately 14,000 students. African American students represent 10\% of the student population, whereas Latin(x) represent $41 \%$ of the student population. The average age of students ranges from 19 and 40 years, where $27 \%$ of the student population is 19 or younger; about $50 \%$ of students are low-income; $75 \%$ of students are first-generation students. The data at Progress College mirrors that of the California community college student population ("California Community Colleges 2018 Student Success Scorecard," n.d.). At Progress College, the student population of African American and Latin(x) at the entry to 
STEM major closely reflects their representation in college, whereas Latin(x) students ( $50 \%$ of the student population) are over-represented in Allied Health classes. The firstyear chemistry class is a prerequisite to higher-level courses. Sadly, it becomes a gatekeeper for students' dreams, persistence, and success due to the low success rates of underserved students in this class.

This study examined my pedagogy in introductory chemistry for Allied Health majors. Typically, I taught a double section of this class of approximately 50 students in a semester. The average pass rate of my classes (introductory chemistry) from fall 13 to fall 18 was $77 \%$, from spring 13 to spring 18 , was $84 \%$, and from summer 13 to summer 18 was $89 \%$. I consider grades of $\mathrm{A}, \mathrm{B}$, and $\mathrm{C}$ as passing grades. Most of the students $(32 \%)$ in my classes are pursuing a nursing degree. The rest of the students are pursuing dental hygiene, kinesiology, radiology technology, chiropractic, nutrition, and health sciences.

My sample population for this self-study was the students enrolled in my Introductory Chemistry course in the Allied Health Pathways in spring and summer 2019. This course consisted of a double-section of approximately fifty students in each semester in Progress College. The spring semester was seventeen weeks long. The students met twice a week for the lecture, and once a week for the laboratory. The summer semester was five-weeks long, where students met every day for four days a week for lectures and laboratories. Although the number of contact hours remained the same, the summer session seemed more intense and could easily overwhelm students. 


\section{Ethics and Research}

The student population for my research study was adult students enrolled in an introductory chemistry course in the community college. At the start of the interview, I asked their permission to interview them. I interviewed adult students using pseudonyms selected by them to protect their identities. I audio-recorded the interviews, transcribed them using zoom technology, and used them in my research studies. My proposed study was considered exempt from review because it was a self-study of my practice intended primarily to improve my teaching. It was also considered low risk because it involved normal educational practices, and the identities of participants collected were treated as confidential. My research data included pretest surveys, exit tickets, interviews, posttest surveys, student pass rates in my class, and my field notes.

\section{Pedagogical Overview}

I planned to modify my pedagogical strategies in a qualitative study to find out what students thought of them, how they performed as a result of these strategies, and how it impacted my teaching practice. I had observed that students report understanding some topics when explained in the class but were unable to retain conceptual significance when they needed to apply the ideas during assessments. The difference between ionic and covalent compounds and their nomenclature was one such example. The naming of ionic compounds has a set of rules, whereas naming covalent compounds has another. After learning the concept, students retained incomplete information, and they mixed up the rules and ended up misnaming them. I needed to change my pedagogy to help the 
students successfully access their learning and clarify the concepts in a way that they do not need to regurgitate the information.

\section{Procedure}

I collected the data in the introductory chemistry course in Allied Health major in a community college. I asked students' anonymous comments in the form of an exit ticket, collected three times in a semester at the end of the lecture. I interviewed students in the laboratory. I evaluated student learning by giving them a pretest on the first day of the semester and a posttest survey on the last day of the semester. I compared their pass rate in my classes from spring and summer semesters of 2019 to the previous semesters. I collected the data in the spring 2019 and summer 2019 semesters.

The students' feedback in the anonymous surveys, in anonymous exit tickets, and focus group interviews provided their experience with active learning infused in culturally responsive practices, which answered my first research question. The student pass rate in my spring 2019 and summer 2019 compared to that in my previous classes also answered my first research question. My field notes answered my second question of how does focusing on CRP changed my stance as a chemistry instructor?

\section{Data Sources}

Classroom teaching and the classroom environment affect student learning. I allowed student voices to direct my research rather than depending primarily on my perception of effectiveness. To check for students' responses, I focused mainly on the 
stoichiometry in a chemical equation. My teaching pedagogy included an interactive lecture with the application of TPS strategy, and group study, all within the culturally responsive pedagogical framework. I explained the selected topic, followed by studentcentered activities. At the end of my lecture, I asked students for their anonymous feedback using exit tickets. An exit-ticket was a form of Likert scale survey (Appendix A), where students responded to a broader question of which interactive strategy they perceived as the most effective in supporting their learning. It also had an open-ended question, where students could write their perspective of an effective pedagogical strategy. The exit-tickets gave me a general idea of students' perception of effective interactive pedagogy. The anonymous exit tickets were collected three times a semester, both in the spring and the summer semester. I took a pretest survey on the first day of the semester and a posttest survey on the last day of the semester to see the impact on interactive pedagogies on student learning. My sample population for the pretest survey, exit tickets, and the posttest survey consisted of approximately 48 students each semester. However, I did not use pretest in the spring semester since it was not ready at the beginning of the semester. Both anonymous pretest and posttest surveys and anonymous exit-tickets were credible since they protected students' identities, and students could provide their feedback without the fear of retribution.

The feedback in exit-tickets helped me structure my interview questions. The focus group interviews were semi-structured, where I asked open-ended questions based on students' responses on exit-tickets (Seidman, 2013; See Appendix D for interview questions). I interviewed six students in the spring semester and twelve students in the 
summer semester in a focus group setting, where students provided their feedback on the impact of my pedagogy on their academic learning. Students self-selected themselves and participated in my study at their will without any extra credit or privileges given to them.

Table 1

Student selection in Spring semester

\begin{tabular}{|c|c|c|c|}
\hline \# Students & Section & Pseudonym & Grade at Completion \\
\hline 1 & 1 & Bob & $\mathrm{B}$ \\
\hline 2 & 1 & Isabel & $\mathrm{W}$ \\
\hline 3 & 1 & Yemi & $\mathrm{B}$ \\
\hline 4 & FY7 & Karen & A \\
\hline 5 & FY7 & Paco & B \\
\hline 6 & FY7 & Ryan & $\mathrm{C}$ \\
\hline
\end{tabular}

In the spring semester, I opted for convenience sampling, where I asked students to volunteer for my study at their will for no extra credit. A total of six students volunteered, three from each section in the spring semester. The participant selection happened to be a diverse group of volunteers in which one student was excelling, and one was struggling, whereas others were in the average range. At the end of the semester, one received $\mathrm{A}$ grade, three got $\mathrm{B}$, one got $\mathrm{C}$ grade, and one student withdrew (see Table $1)$. 
Table 2

Student selection in Summer semester

\begin{tabular}{|c|c|c|c|c|}
\hline \# Students & Section & Pseudonym & Grade at Selection & Grade at Completion \\
\hline 1 & 51 & Ana & $\mathrm{B}$ & $\mathrm{B}$ \\
\hline 2 & 51 & Jesus & $\mathrm{A}$ & $\mathrm{B}$ \\
\hline 3 & 51 & Pablo & $\mathrm{C}$ & $\mathrm{C}$ \\
\hline 4 & 51 & Poncho & $\mathrm{A}$ & $\mathrm{C}$ \\
\hline 5 & 51 & Sammy & $\mathrm{C}$ & $\mathrm{C}$ \\
\hline 6 & 51 & Tinkerbell & $\mathrm{D}$ & $\mathrm{W}$ \\
\hline 1 & 52 & $\mathrm{AJ}$ & $\mathrm{B}$ & W \\
\hline 2 & 52 & Alice & $\mathrm{A}$ & $\mathrm{A}$ \\
\hline 3 & 52 & Big Tuna & $\mathrm{B}$ & $\mathrm{C}$ \\
\hline 4 & 52 & Chalino & A & $\mathrm{A}$ \\
\hline 5 & 52 & Shantal & $\mathrm{C}$ & $\mathrm{C}$ \\
\hline 6 & 52 & Tony & $\mathrm{C}$ & $\mathrm{C}$ \\
\hline
\end{tabular}

In the summer semester, I decided to expand the number of participants to get more reliable data. Students again self-selected them, but I intentionally selected a diverse group for focus group interviews. I made sure they represent a wide population of their class standing. I selected a total of twelve volunteers, six from each section. At the time of selection, four students were getting A grade, three were getting B grade, four were getting $\mathrm{C}$ grade, and one was getting $\mathrm{D}$ grade. However, at the end of the semester, 
two received A grade, two $\mathrm{B}$ grade, six received $\mathrm{C}$ grade, and two ended up withdrawing the class (see Table 2).

The focus group interviews were held in a group setting for approximately an hour in the laboratory, three times in the spring semester, and two times in the summer semester. Before recruiting students for a focus group interview, I informed them that they would not get any extra credit for their participation in my study, and their academic standing would not be affected by their responses in the interviews. This assurance would reduce the risk of students wanting to please me. I believed the focus group interviews gave validity to the data since it had the power to shift the balance between students and instructors.

The students' responses in their pretest and posttest surveys, exit tickets, interviews, and their pass rates triangulated the data. The four data points provided me a holistic picture of students' perceptions of the impact of my interactive pedagogy on their academic learning, which answered my research question 1. Being a participant in the study, I evaluated my teaching and recorded my progress. I kept reflecting on my thoughts in my field notes throughout the semesters. During my lecture, I observed student engagement in the classroom and reflected in my field notes. I reflected on the impact of my teaching practices on my students and myself. I was interested in finding the effect of changes in my pedagogy on myself or my teaching practices, which answered my research question 2. My field notes provided me with my perspective on the impact of interactive pedagogies on student engagement. They also informed me about my transformation as a chemistry professor. 


\section{Potential biases based on positionality}

My position as an instructor during the research process was critical to the selfstudy process, but it also had potential risks. Since I was interviewing my students, I was mindful of the fact that students might try to please me and say the things I want to hear, which might compromise the data. To resolve this problem, I emphasized the voluntary, non-evaluative nature of the interviews and the role they would play in improving my instruction for the students in the course. Also, the use of anonymous exit tickets provided an opportunity for students for their feedback without the risks they may feel in critiquing my pedagogical choices directly.

\section{Data Analysis}

From the literature, I know that traditional teaching is ineffective. I analyzed supportive pedagogical practices to find their impact on student learning (Christians \& Carey, 1989). For qualitative analysis, my data included pretest and posttest surveys, exit tickets, and interviews, which gave me the student perspective. I recorded and transcribed the students' interviews. I used the Zoom app to record and transcribe interviews. I had my field notes on the instructor's perspective. I used Microsoft Word and Microsoft Excel software for qualitative data analysis.

After collecting the data, I found specific patterns, which students' quotes produced. The patterns resulted in codes and their definitions (Saldaña, 2015). I coded data multiple times. I developed a codebook where students' common quotes or repeated statements were grouped under specific codes and then counted for frequency. When all 
the codes put together from multiple cycles of coding of students' remarks on the anonymous surveys and exit tickets, interviews, pass rates, and my field notes, I processed the data through the students' lens and my own instructor's lens. I grouped the codes into categories (Saldaña, 2015).

My findings of teaching and learning were directly related to the student classroom experience. The findings in my classroom gave me an insight into effective teaching pedagogy in an introductory chemistry course. Student feedback on culturally responsive practices and active learning strategies, such as instructor demeanor, use of relatable examples, application of TPS strategy, group work, along with student pass rate, answered my first research question. My anecdotal notes on students engaging during the class session and throughout the semester gave me my perspective on the impact of interactive pedagogies on student engagement. It also explored a change in me as a person and my stance as an educator. As a chemistry professor, my goal was to cover the entire material guided by our curriculum and deliver my lecture in a way that students understand. The dialogic pedagogy using examples from students' familiar experiences, made me think about how chemistry should be taught. My field notes showed me how my stance as a chemistry professor changed? I reflected on my experiences in the classroom and noticed if a change in my teaching practice had any effect on student engagement. I found out how my practice got impacted as a result of this research. I know this research was time-consuming. Reflecting on the impact of my teaching, retrieving exit tickets, and interviewing students took considerable time away from my 
scheduled lecture time. However, I considered it as an investment for student classroom engagement in the introductory chemistry course in a community college.

The limitations in my data collection phase included when students were not willing to participate in the interview or exit tickets since it was additional work for them. It was especially significant in summer, where students were not interested in the interview the second time. The summer semester was short, condensed into five weeks only, and as such, students were pressed for time. To accommodate them, I interviewed them twice instead of three times as scheduled initially.

\section{Summary}

This chapter discussed the details of the methodology used in this self-study. In designing this study, I built upon the work of previous scholars who had used similar approaches to examine and change their practices. This research was a self-study to improve my teaching practices to enhance CC student's achievement in introductory chemistry class. I focused specifically on my efforts to integrate active learning strategies into culturally responsive practices. I applied supportive pedagogical practices, such as instructor demeanor, relatable examples, classroom environment, TPS, and group study. I selected the topic of stoichiometry based on my experience, which I considered a struggling matter for students. I analyzed students' responses using exit tickets, pretest and posttest surveys, and focus group interviews. I compared the pass rates of my classes in spring and summer 2019 to the pass rates in previous semesters to evaluate student achievement. I will present the findings from this data collection in the next chapter. 


\section{Chapter Four: Report of Findings}

In this self-study, I sought to examine how elements of culturally responsive pedagogy and active learning strategies influenced student learning in a challenging chemistry concept in a community college classroom. Student focus groups, reflective exit tickets, and my field notes were the primary source of data collection. The data were collected in the spring and summer semesters of the 2019 school year at Progress College. The sample population was the students enrolled in the introductory chemistry class in Allied Health pathways. The spring semester was structured in seventeen weeks. Students met twice a week for one hour of lecture and once a week for three hours of lab. The summer semester was condensed to only five weeks. Students met for two and a half hours of lecture and two and a half hours of lab every day four times a week. To collect data, I asked students if they would volunteer to participate in a focus group. Focus groups were conducted two to three times during each spring and summer semester. The exit tickets were collected three times each semester. Focus groups and exit tickets were designed to identify how elements of culturally responsive pedagogy and particular active learning strategies influenced student learning about stoichiometry.

I attempted to integrate elements of culturally responsive pedagogy and specific active learning strategies during classroom instructional time. The aspects of culturally responsive pedagogy I referred to included instructor qualities, use of relatable examples, and classroom environment/community building. Specific active learning strategies I utilized included think-pair-share and group study. 
This chapter will illustrate how I incorporated particular active learning strategies within the identified elements of CRP. The identified active learning strategies are thinkpair-share strategies and group study. The identified elements within CRP are instructor qualities, relatable examples, and classroom environment/community building. The following sections are as follows: The Challenge of Stoichiometry in Introductory Chemistry, The Teaching of Stoichiometry and My Own Development as An Instructor, Culturally Responsive Practices and Active Learning Strategies to Support the Learning of Stoichiometry, and Analysis of Student Response to Culturally Responsive Practices and Active Learning Strategies in Stoichiometry Unit.

\section{The Challenge of Stoichiometry in Introductory Chemistry}

Stoichiometry is an essential component of introductory chemistry. According to Okanlawon (2008), stoichiometry is a concept that involves problem-solving skills and retention of previous knowledge. Zumdahl and DeCoste (2018) define stoichiometry as the determination of interchangeable relationships of mass and mole quantitatively. In other words, stoichiometry is a blend of chemistry and introductory algebra contents, which are required for students to learn stoichiometry. Students are introduced to stoichiometry after they have been exposed to chemistry concepts such as atoms, molecules, nomenclature, and balanced chemical equations and algebra concepts, such as dimensional analysis using scientific notation and units.

The knowledge acquired through learning the broader concepts associated with stoichiometry is essential for students. I have taught all levels of chemistry courses in a 
community college, and I have observed that in all higher-level chemistry courses, students synthesize this knowledge of stoichiometry and use it to find limiting reagent, percent yield, and percent error in the lab experiments. These calculations can only be performed if students are comfortable with moles, mass, molar mass, and Avogadro's number, which are the essential components of stoichiometry. Therefore, stoichiometric calculations are not restricted to the introductory chemistry course, but they are used in all higher-level chemistry courses. Bridges (2015) claimed, "Improving student achievement in stoichiometry can lead to a deeper understanding of chemistry, one of the most challenging courses in science, and a potential increase in students majoring in science and technology-related fields of study at the postsecondary level" (p. 12). I decided to zoom in on the topic of stoichiometry because students' success in stoichiometry in the introductory course prepares them to be successful in upcoming higher-level chemistry courses. If students can conceptualize the process and synthesize the information to solve problems related to stoichiometry, it can become a gateway to higher-level concepts (Bridges, 2015).

The stoichiometric concept is a stumbling block for students. In stoichiometric calculations, students need to interconnect knowledge, use prior learning, and synthesize new knowledge. (Fach et al., 2007). According to Ayoade (2012), “Solving stoichiometric problems requires stringing together many steps using conceptually organized knowledge" (p. 147). The student needs to interpret the information, identify the entities involved, and plan a comprehensive pathway using reasoning. According to 
Fach et al. (2007) and Ayoade (2012), conceptual difficulties are revealed when students are unable to

1. extract information from the given problem

2. realize that a chemical equation must be balanced

3. calculate molar mass using the mole concept

4. relate moles of a given substance to the mole of the desired substance

5. relate mole to Avogadro's number

6. calculate mass using the mole concept

7. identify limiting reagent

8. retain prior information to construct the meaning of new knowledge.

The concept of stoichiometry begins with the definition of the mole. The mole is a specific exponential number $\left(6.023^{*} 10^{23}\right)$. Students can do simple math in their head without using a pen or pencil. They can easily see two dozen eggs as twelve eggs.

However, they are unable to see one mole as $6.023^{*} 10^{23}$ particles and two moles as two times that number. Somehow, they end up assuming that one mole is the same as one particle. According to Hand et al. (2007), "the mole, an embedded concept in the topic of stoichiometry (Dierks et al., 1985; Gower et al., 1977; Guthrie, 1991) is identified as the most difficult part of an introductory chemistry course" (p. 125). No doubt, students find the stoichiometric concept difficult; it is also a challenging topic for instructors to teach.

\section{The Teaching of Stoichiometry and My Own Development as An Instructor}

As a chemistry instructor, I have witnessed students' struggles with understanding 
the concept and relevance of stoichiometry. Several studies show that a stoichiometric topic is difficult for teachers to teach and for students to learn (Fach et al., 2007; Evans et al., 2008; Ayoade, 2012). Traditional pedagogy is one of the reasons students struggle with understanding the concept and relevance of stoichiometry. Traditional pedagogy is defined as a "teaching by telling" approach where instructors transfer information to students who are the recipients of the information (Freeman et al., 2014). When students learn by rote memorization, it results in incoherent knowledge. In a traditional lecture-based approach, the instructor focuses on step-by-step algorithmic problem-solving in stoichiometry instead of conceptual understanding of the subject. Students will more than likely memorize the steps to solve a given problem but struggle to comprehend the overall concept of stoichiometry. As a result, students are unable to transfer knowledge learned from one context to another (Ayoade, 2012). As a result, students are likely to become less motivated and disinterested in the topic of discussion (Fach et al., 2007).

Additionally, students are typically taught problems such as mass-to-mole, moleto-mole, or mole-to-mass through an algorithmic approach that negatively impacts their ability to view these as interconnecting concepts (Hand et al., 2007). The terms, such as mole, molecule, molar mass, and mass sound similar. If students are unable to connect prior knowledge to new information, it is easy to get confused in the similar-sounding terminology.

I have been teaching an introductory chemistry course for many years and every 
semester I observe many students struggling with stoichiometry. I used to teach this unit with a mathematical approach in my prior classes, but students often began to disconnect as soon as I started talking about the mole. Bridges (2015) observed a classroom where the teacher was teaching stoichiometry, but students were not applying the concept to synthesize information and solve the problem. I incorrectly assumed this disconnect due to poor math skills, believing this to be the only stumbling block for their success. I was so convinced of this interpretation that in the first year of my doctoral program, I focused my efforts on improving students' math skills for downstream success in chemistry. These initial efforts were based on several studies claiming poor math skills as the primary reason for student failure in chemistry (Leopold \& Edgar, 2008; Scott, 2012). However, as I progressed in my doctoral program, my views on student struggle began to change. Math aside, traditional pedagogy is another stumbling block for student academic persistence and success (Seidman, 2005), as teaching practices can lead to student success or failure in their career pathways irrespective of their math skills (Freeman et al., 2014). In this research, I decided to re-examine my teaching practices to find what works and what does not for many students in my introductory chemistry class.

Previously, I would follow the logic given in the textbook to explain the stoichiometric concept and replicate the solved example given in that textbook. I used to describe the pattern in an organized, step-by-step manner, checking for student comprehension periodically. If confusion followed, I would repeat my explanation and encourage the student to review the presented example from the textbook for further clarity. I would also assign a worksheet with similar problems for students to practice at 
home for more repetition and to serve as a preview for an upcoming quiz. Lastly, I would review the concepts in class one last time before the exam.

I observed that if students remembered algebra skills covered in class, they would do fine. However, if I changed the wording in the problem, some students no longer recognized what was being asked for. They preferred the text in the exam to be like that in the worksheet, as it allowed them to replicate the process as memorized. It appeared that students were unable to see the whole picture and had instead compartmentalized information. They were unable to connect the separate compartments of information to solve a problem with the same underlying concept but presented with different wording.

As a result, I decided to focus on a more culturally responsive practice (CRP) infused with active learning strategies (ALS). A culturally responsive pedagogy creates a classroom environment where students learn in collaboration (Ladson-Billings, 1995), while active learning helps generate more profound knowledge in students (Auerbach \& Andrews, 2018). Now, I will talk about these strategies in detail.

\section{Culturally Responsive Practices (CRP) and Active Learning Strategies (ALS) to Support the Learning of Stoichiometry}

The following section will detail the active learning strategies I incorporated in my recent teaching. First, I will focus on a culturally responsive framework. Then, I will describe how the elements of active learning existed with a culturally responsive framework. Next, I will use excerpts from student focus groups and exit tickets to help illustrate the impact of my teaching through a culturally responsive framework and using 
the identified elements of active learning. I end this section with my anticipation of the impact of these practices on student learning.

Over time, through critical self-reflection and student feedback, I noticed how my teaching patterns were more aligned within a traditional pedagogy framework. I began developing my practitioner lens and gaining a deeper understanding of equity, leadership, and student-centered learning environments during my second year in the doctoral program. Subsequently, I was inspired to improve my pedagogical approach. I learned about various theories, such as culturally sustaining pedagogy, critical race theory, culturally responsive pedagogy, and active learning. Enriching dialogue with peers about how they were processing mental and emotional work while turning theory to practice intrigued me to learn more about how I could use certain aspects of culturally responsive pedagogy, and particular elements of active learning to improve my pedagogical approach. My hope was to improve my practice in a way that would ultimately have a positive influence on the learning experiences of students, particularly students who were identified as underserved during or prior to enrolling in my class.

According to Gay (2002), culturally responsive pedagogy is defined as "using the cultural characteristics, experiences, and perspectives of ethnically diverse students as conduits for teaching them more effectively" (p. 106). Scholars such as Ladson-Billings (1995), and Nieto and Irizarry (2013) have highlighted the aspects of instructor qualities, relatable examples, and classroom environment as important elements within the CRP framework. Each of these CRP elements was used for this current study. Specific active learning strategies were also used for the current study. According to Graham et al. 
(2013), “Active learning includes any activity in which every student must think, create, or solve a problem" (p. 1456). Active learning is often used to support students toward higher levels of thinking critically about a given concept. Similar to CRP, active learning is the contrast to traditional pedagogy. The three identified aspects of the CRP framework were used in relation to the two active learning strategies for this study. I focused on the following CRP elements: instructor qualities, the use of relatable examples, and classroom environment/community building. I also concentrated on the next active learning strategies: Think-Pair-Share and Group Study. Each of the identified elements and strategies will be further described below. I will also explain the importance of these elements and strategies and how I implemented them in the class setting.

\section{CRP: Instructor Qualities}

The quality of interactions between instructor and student are essential to student engagement, and their desire to push their learning inside and outside the classroom. It is critical that students are able to make their learning transferable, from the classroom to their lived experiences outside the classroom. A CRP framework can help foster the learning spaces students need to make their knowledge transferrable. Thus, it is essential that instructors embody personal qualities that validate the social and academic experiences of students. Aceves and Orosco (2014) suggest instructor qualities are important components of CRP. They suggest instructor qualities can include acts of care and respect, and to be an interactive instructor who can be receptive to student questions while utilizing collaborative teaching methods. 
For this study, I took specific approaches to show students I cared. One specific approach was by prioritizing student input. For instance, after working with peers on a problem relating to a certain concept, I authorized students to decide if they needed additional problems with added complexity or if they were ready to progress to the next concept. I also attempted to demonstrate acts of care. For instance, I encouraged students to share their thinking and with the group as a whole. I tried to include students through this act of care. In this context, inclusiveness can be an explicit way to show others they are important and that they are cared for (Exline et al., 2012). Each student was verbally celebrated by their peers and me after they shared with each other or with the larger group. This explicit act of care occurred for a majority of our class time, including during my lectures and while students were in collaboration with their peers. Hurtado et al. (2011) posited that frequent interactions lead to student success. For students, frequent interactions meant that they were not lost in their struggle; their instructor was accessible to provide the necessary support. This experience motivated them and led them to excel in the academic environment. Thus, for this study, I attempted to interact with students on a regular basis, and as often as the opportunity was presented.

\section{CRP: Relatable Examples}

Generally speaking, relatable means something being related to something else, or a person being able to relate to something or someone. In this context, a relatable example is something the instructor does, says, or provides that is general enough that the student is able to make a connection with what the instructor offers. For instance, I 
attempted to provide a relatable example when I was explaining the properties of the acid. When an ant stings, it hurts, and we feel the burning sensation. It is because the ant injects formic acid in self-defense. It was my attempt for students to connect the corrosive properties of acid to the sting of an ant. As stated by Willingham (2003), students' thinking is stimulated when instructors utilize activities that help students make explicit connections to their lived experiences. I attempted to connect all new concepts to generalizable examples that students could relate to. For instance, one relatable example I used was a "Goody Bag” example. I will go into further detail about this particular example later in this chapter.

Regularly, I encouraged students to do their best, and think of at least one example of their own that they could connect with the concept we were learning in class. I advised them that they could think of any day-to-day experience and link it with the science concept. I showed them how I connected my experience of getting coffee in the morning to the homogeneous property of the mixture. A homogeneous mixture is a type of mixture where all the components are mixed uniformly. When I bought coffee, I observed that it had water, caffeine, milk, and sugar. Since everything was mixed thoroughly in the coffee, I could see that it was a homogenous mixture.

I observed student interactions to check if they were connecting the science concepts to their familiar experiences. I initiated the conversation on a related topic, and I provided an example associated with it. Then, I invited students to contribute to that example or conversation. If students participated enthusiastically, I felt they were able to connect it to their familiar experiences. If I observed that they were not responding, I 
either gave them another example or asked them to come up with an example. From student engagement, I inferred that students could relate the examples to the abstract concepts.

\section{CRP: Classroom Environment/Community Building}

Classroom environments are essential to student success, no matter the grade level. Therefore, it is important for instructors to be intentional about creating a welcoming classroom environment. A welcoming classroom environment is a space where students can fully participate in discussions and activities without any fear of repercussions. It is created through social norms and values rooted in respecting self and others. Welcoming classroom environments are maintained through communal agreements, having real expectations among group members, providing ample support for all members, and having all members of the group work toward a common goal (LadsonBillings, 1995). The practice of creating and maintaining a welcoming classroom environment happens through community building. A qualitative study by Godwin and Potvin (2017) illustrated the importance of the classroom environment and community building. Scholars demonstrated how a participant in the study was able to excel in high school due to the classroom environment, and that students in the study were intentional about building community and working together towards a common goal. When the student from the study transferred to the college, where she was not able to experience a welcoming classroom environment, she decided to leave the STEM field altogether. A welcoming environment is essential to student learning and persistence. 
In my attempt to create a welcoming environment, I incorporated multiple strategies, such as think-pair-share and relatable examples. Think-pair-share was a strategy used to increase student-to-student interaction. The student-to-student interaction involved dialogue and probing questions about the topic students were studying. The use of relatable examples was another way to increase student participation. Students used relatable examples to make explicit connections to the complex content. Student participation and discussion signified welcoming classroom discussions.

\section{ALS: Think-Pair-Share}

Think-Pair-Share (TPS) is an activity that allows students to think, to engage in discussion, and to make their thinking visible for others. In this context, the instructor provides students with a concept associated with the day's lesson. The instructor gives students several minutes to think about the concept individually. Next, students are asked to pair up with a neighbor and share how they are thinking about the concept that was presented by the instructor. During the pair-share, students are encouraged to actively converse to construct new knowledge about the concept that was presented by the instructor. Kothiyal et al. (2013) found that the TPS strategy can increase student engagement. I attempted to implement the TPS strategy by reformatting my lesson plan such that students spent most of their time in activities during each class period.

To explain new concepts, I used relatable examples with students' input and then used the TPS strategy for students to work on mathematical problems using critical thinking (Brame \& Director, 2016). First, students were provided time to think about the 
problem individually. After several minutes of individual think time, students were asked to find a partner and to collaborate and reflect on their thinking. Students were also asked to receive immediate feedback from their peers about their understanding of the problem. Students were then asked to share their thinking and understanding of the new concept with the entire class. Important to note, my mathematical problems were no longer derived from the textbook - many times, I asked students to synthesize a problem in the class, which I never did in my previous years of teaching. When students asked for a review on stoichiometry before the exam, I advised them to write any equation, assign arbitrary quantities to reactants, and solve the problem to find the mass of the product.

\section{ALS: Group Study}

In a group study, students work collaboratively in teams of roughly 4 - 6 students per group. New knowledge can be generated through guided group discussions. In their qualitative research for active learning in large classrooms, Auerbach and Andrews (2018) proposed that students learn better when they work in collaboration and provide reasoning instead of coming up with the correct answer. I offered the worksheet (See Appendix E) and asked students to share their ideas in their designated groups. The worksheet had multiple problems, which students could only solve by critical thinking. All the problems had different complexities. If students had memorized certain steps, they would not be able to see the connection among concepts and would not be able to construct the knowledge. When working in a group, each member would contribute to the discussion by sharing their thought processes and see the whole picture. I hoped to increase student-to-student interactions, and ultimately, create a space for students where 
deeper learning could occur. On occasion, I gave the entire lab period to students to work in groups on these worksheets. Although I posted worksheets with detailed answer keys on College Dashboard - Canvas, I advised students to use the answer keys as a last resort. Instead of giving students a review in class before the exam, I suggested the following to students: collaborate in groups, synthesis questions, solve problems, and discuss ideas with peers.

I hope that by using elements of CRP and ALS mentioned above that students will gain a deeper understanding of the concepts that were studied. I anticipate the “instructor's qualities" - acts of care and respect, to be an interactive instructor who's receptive to student questions, and utilizing collaborative teaching methods - will increase student-to-instructor and student-to-student interactions and motivate students to succeed (Mesa et al., 2014). An inviting classroom environment with enhanced interactions will draw students to the classroom and increase their attendance and participation (O'Keeffe, 2013). I hope that connecting the complex topic to students' familiar experiences will stimulate their ability to conceptualize and that it will help in the retention of information (Willingham, 2003). I expect that TPS will motivate students to think critically.

\section{Analysis of Student Response to Culturally Responsive Practices and Active Learning Strategies in Stoichiometry Unit}

This section will cover how I taught stoichiometry using CRP and AL strategies, 
and students' feedback on the ALS strategies mentioned above. Although my teaching practices were consistent in both spring and summer semesters, the pace of my lectures was much faster in the summer semester due to time constraints. Upon reflection of my teaching practices over the spring and summer semesters during the time of this study, I realized my teaching approach was a blend of interrelated practices. As a result of the lively classroom environment, I needed to be responsive to the needs of students individually and as a whole. Below, I will describe what occurs in one day of my classroom in the spring semester, when I lectured on the mole concept, which I recorded in my field notes.

The class starts at 7:30 AM. I greeted students by asking how they were doing that morning as they walked into the classroom and settled in their seats. I then engaged with students in a casual conversation. For instance, a question I asked students was if they encountered traffic on their way to the college. Then, I asked students if they had any questions about the previous lecture that I could help them with. I also used this opportunity to allow students to catch up with any missed information by discussing it in class.

It was soon time to introduce students to the stoichiometric topic. I informed students that the stoichiometric concept was a marriage of math and science. To understand the stoichiometric concept, students would need to refer to prior information about atoms, molecules, and dimensional analysis, and use their critical thinking skills to synthesize new information. Students were also welcomed to use a calculator to solve complex stoichiometric problems. 
First, I introduced the mole concept. Next, I provided a relatable example by comparing a mole to the dozen concept. I equated "mole" to "a dozen," with the hope that students would relate to as follows:

Just as 1 dozen chairs $=12$ chairs, 1 mole chairs $=6.022 * 10^{23}$ chairs

Just as 1 dozen $\neq 1$ chair, 1 mole $\neq 1$ chair.

A mole is an exponential number. Because students never use exponential in their daily lives, I attempted to use something that students were more familiar with to make a connection to exponential numbers. I assumed that most students enjoyed attending birthday parties, and who doesn't like to receive a goody bag in return? I used a class activity called "The Goody Bag Example" (See Example 4.1). For this activity, I invited students to come up with the contents for the goody bag. I observed an increase in students' level of excitement, the more they engaged in the activity. I anticipated that once students understood the difference between the making of one goody bag and the making of one dozen goody bags, they could extend their understanding to the difference between one molecule and one mole of molecules. In this example, I created a classroom environment that I hoped would be inviting for students so they could interact with me freely and engage in learning by connecting the abstract concept to familiar experiences, all of which were the components of CRP.

I spent the first twenty minutes of class to explain the mole concept to students. I stopped multiple times throughout my explanation to ask students, "Did it make sense?", “Are you with me?" "Did you have any question?" and/or "Did you need more time?" One of the instructor qualities within the CRP framework is taking time during the 
explanation of the concept to be receptive to students' needs. I proceeded to the following problem when multiple students responded in affirmation. I advised students to work in collaboration using the TPS strategy. The problem read: "How many molecules are in 8.0 millimoles of water?"

This was the first problem that could help illustrate if students understood the concept of mole and its connection with molecules. At this point, students could also check their understanding of the mole concept, particularly if they could connect prefixes to units and understand the application of significant figures. For the first few minutes, the students were quiet. I could only hear flipping pages, students' backpacks opening, and calculator covers opening. At this time, students were looking at notes they had previously taken to refresh their memory. They were given time to process the information independently and utilizing the calculator to work through the problem.

I strolled throughout the classroom while students pursued trying to understand the problem that was presented. I noticed students were more likely to ask a question if I was in their working vicinity. This responsive strategy also allowed me the flexibility to answer students' questions as they were requested. After about ten minutes, students began talking with their peers. I observed if everyone was talking to a peer. In case a student was sitting alone, I asked that student to sit with someone so that the pair can collaborate. I reminded all students to sit and discuss with partners. Conversations gradually increased over time. Now, my class was noisy. I could see students engaging with peers. I continued to monitor their levels of engagement by observing which students were talking more, who made connections, who used relatable examples, and 
who pushed their peers to think critically about the topic of discussion. It was the example of a TPS component of an active learning strategy.

I kept on monitoring students' interactions with each other when students were engaging with peers. If I noticed a pair had finished discussing the problem, I would split the couple and send them to students who needed support. Sometimes, I asked the pair to locate struggling students themselves and approach them to help. Such an intervention represented my efforts in promoting student-to-student interactions and collaborative learning aspects of the instructor qualities within the CRP framework. When I observed that most of the class was done working with the problem, I invited a few representatives to share their thought process with the class. I observed students shared their critical thinking skills with class freely. Finally, I would go over the problem if students wanted me to share my thinking with them. This exercise reflected my attempts to build a welcoming classroom environment with a caring instructor who valued students' input, which was the components of CRP.

I assumed I could proceed to the next topic. I checked with students if they were ready. I asked them, "Should I move on to the next topic?" In response, students asked for another problem to get comfortable with their problem-solving skills. I honored their request and assigned them another problem to work using TPS strategy instead of proceeding to the next topic. My prioritizing students' input reflects my caring attitude, a component of CRP.

Although I gave another problem, I added complexity to it. I did not want students to practice a similar issue; instead, I wanted them to challenge them in their 
critical thinking skills. I gave them the following problem and asked them to work in collaboration using TPS strategy. The problem read: "How many atoms of hydrogen are in 8.0 millimoles of water?" The added complexity provides a platform for students to comprehend the information, see the whole picture, and be able to construct new knowledge. It was an example of an active learning strategy.

\section{Example 4.1}

\section{The Goody Bag Example}

First, I asked students when they were young, how did they use to celebrate
their birthdays? Many students responded and contributed to the discussion. In the
end, it came out that they sometimes they invited their friends, had food, cut cake,
received gifts (many students laughed here), played games, and gave goody bags when
their friends were leaving. I proposed to students that a child is celebrating his
birthday and he has invited us all for his birthday party. He decided to give each of us
a goody bag. I asked students what they wanted in their goody bag. One student
replied a pencil, and another one said she wanted candies. I wrote the following
equation and asked them what it meant for them.
1 pencil

Jenna correctly interpreted that she added one pencil and two candies in a goody

bag. I asked the students if the birthday boy had invited twelve friends, how many goody bags would he need to make? To which, students instantly replied twelve goody bags. Then we continued to the number of pencils and candies required for twelve 
goody bags. Students were comfortable figuring out the number, and finally, they wrote the equation (1) in terms of dozen as follow

1 dozen pencils $+\quad 2$ dozen candies $\quad \rightarrow \quad 1$ dozen goody bags

I asked them if we could interchangeably use the terms "1 goody bag" and "1

dozen goody bags." Students were confident in saying that we could not mix numbers with dozens. Everything seemed to be working perfectly. Now I wrote equation (3) on the board and explained to students that this equation could be interpreted in terms of numbers or moles, just as numbers and dozens above. We could read equation (4) in terms of numbers and equation (5) in terms of moles, but we could not mix molecules with moles.

$2 \mathrm{Na} \quad+1 \mathrm{Cl}_{2} \quad \rightarrow \quad 2 \mathrm{NaCl}$

2 atoms $\mathrm{Na}+1$ molecule $\mathrm{Cl}_{2} \rightarrow \quad 2$ molecules $\mathrm{NaCl}$

2 moles $\mathrm{Na}+1$ mole $\mathrm{Cl}_{2} \quad \rightarrow \quad 2$ moles $\mathrm{NaCl}$

\section{Analysis of Student Response to CRP and ALS}

The following section will describe how elements of Culturally Responsive Pedagogical framework and Active Learning Strategies (ALS) influenced the learning experiences of students in a community college introductory to chemistry course. The points of connection are my teaching practices that students appreciated. The points of resistance are my practices, which students resisted and would like me to revert to traditional pedagogy. 


\section{Points of connection - CRP: Relatable Examples}

Relatable examples were those examples in which students could think about their familiar experiences and connect them to science concepts. Overall, twelve students were present in the second interview on the day when I was covering stoichiometry in class. Three students loved using relatable examples, six students did not like the use of relatable examples to explain the concept of mole, and three students did not comment about it at all. For exit tickets, there were seventy-five students present, seven did not respond at all, and ten students named the use of relatable examples that helped them the most in their engagement. However, they did not mention its use specifically to stoichiometry.

In the following quote, Sammy said that she liked candies, and she liked goody bags. She was referring to the goody bag example (see Example 4.1), which she could relate to her social life by going to birthday parties. The concept of the mole was abstract and difficult to comprehend. However, it became fun for Sammy to visualize the making of goody bags, and she could now associate it with making moles of sodium chloride (see Example 4.1).

You don't always think like chemistry, and moles and stoichiometry will relate to you in any way. But when the teacher talked about how we have goody bags, and we fill them up, and we get a certain amount, it helped because I like goody bags and I like candy, and I like science (Giggles). So, to be able to relate it and bring 
it together is something that will be able to stick into my mind, especially being a kinetic learner and like doing stuff with my hands. (Sammy)

In the exit ticket, a student quoted below the example of Mt. Everest. I inferred that the student was referring to the concept that the boiling point would decrease with altitude. During the class session, I interacted with students to find out if they knew that the boiling point of water at sea level was $100^{\circ} \mathrm{C}$. Most of them were aware of it. Then, I gave them an example that if they took water with them to the Mt. Everest and tried to boil it, it would boil at $71^{\circ} \mathrm{C}$. As a result, they would require more time to cook food since the temperature was lower. I could interpret from the following quote that the student was able to connect the abstract content to the experience outside the classroom. He also was referring to other relatable examples that students were able to think of in the class. He said, "Real-life applications really help me grasp concepts beyond the classroom. For example, the story of Mt. Everest and Boiling Point and Tea and Solutions."

In every lecture, I consistently modeled students to try to connect the concepts to relatable examples, and I advised students to do the same. Studies suggest that it stimulates critical thinking and helps in the retention of information (Willingham, 2003). In the following quote, I inferred that when Jesus was observing nature, he actively associated his observation with scientific knowledge, and as such, he was thinking like a scientist. 
It does help me when the professor gives relatable examples because I could just if I'm just on my day off doing nothing, I'll just think of something random, I'll connect to whatever science, chemistry or math. That way, it reinforces the memory, and it's just random too because I'll look at a tree, and I'll think about carbon dioxide or something like that. (Jesus)

I felt validated when I was listening to Jesus because I wanted students to develop a habit of connecting familiar experiences or everyday' observations of science concepts. However, many students resisted the use of relatable examples to explain the mole concept, which I will discuss later under the section "Points of resistance."

\section{Points of connection - CRP: Instructor Qualities}

Instructor qualities are a component of CRP. They include a respectable, interactive instructor who promotes questioning and collaborative learning in class (Aceves \& Orosco, 2014). In exit tickets and focus group interviews, students brought up many ways in which instructor qualities impacted their learning.

Respectful Instructor. Out of twelve people in the focus group, two students talked about the importance of the presence of a respectful instructor in class, while others did not mention anything about it. Out of seventy-five students present for the exit ticket, nobody named the respect as the most effective contribution to their engagement. In the focus group, for Isabel and Bob, respecting students was so significant that they firmly believed that it had an impact on their academic achievement. Since they did not talk specifically about my demeanor, I infer that they accepted my respectable attitude. 
In the following quote, Isabel strongly believed that if the instructor did not respect students, they would not succeed.

I can start this for the professor; I expect them to be respectful towards the students. I've had professors who are rude or condescending, and it just because it all starts with the professor. I feel everybody sits down; nobody knows each other, but if the professor's warm and welcoming and knowledgeable, then you immediately have a class. If they're not, you just doomed to fail. It's not gonna work. (Isabel)

Interactive. Out of twelve people interviewed, eleven students reported liking techniques coded as "interactive instructor," who was receptive to their inquiries, and who promoted collaborative learning in class. In the exit tickets, out of seventy-five students present, seven did not respond, and twenty-one students named instructor's qualities that helped them most in their engagement. Although their comments were not specific to stoichiometry, their feedback was taken at the time when stoichiometric concepts were studied in class. I could infer that their comments pertained to my demeanor while teaching stoichiometry in class. Shantal was the only student who preferred other means of learning, which were aligned with traditional pedagogy, although she did not challenge the concept of collaborative learning.

Students appreciated the impact of collaborative learning on their understanding of the concepts. Bob believed that working with peer-supported them in figuring out the 
missing information. Besides, he felt when he was able to explain the concept to his neighbor; it signified that he had a sound grip on the subject. Similarly, the following anonymous quote in the exit ticket implies that students appreciated the impact of collaborative learning on their engagement: "Talking to a partner helped with better understanding."

In the second focus group, Chalino and Jesus referred to my interactions with students. They appreciated when I gave the demo in class using student volunteers to explain certain concepts. At times, I gave them 3D models to construct molecular shapes. Such activities supported students in understanding the abstract concept by visualization.

In the classroom, when students were working on the problem with peers, I usually walked around and monitored their activity. I checked with students if they finished working on the problem or if they still were contemplating. I sent students who completed discussing the issue to the students who needed help. In the following quote, Chalino was describing my process of promoting collaborative learning and my intention to ensure that every student learned in class.

...she'll come around, and she will make sure she'll be like, did you do it? Okay. Will you go to help? Oh! You didn't get it. Okay. Will you come here? You help. Like she makes sure, you get it somehow, someway. Certainly, think-pair-share is helpful. That's like a really good thing. (Chalino) 
Poncho, being a shy student, felt that his professors in some classes were not approachable, which was a hindrance to his learning. However, the following quote showed his appreciation of my efforts in creating a classroom environment where I was respectful to students and receptive to their questions. He valued my accessibility that he could ask me any question, and I made sure I answered it.

Something for the shy students, there have been some classes where I don't feel comfortable asking questions because I feel the response I will get from the professor. But in this class, any questions I've asked, the professor will answer it, even if it's repeating herself or something that she just went over. I've had some professors that say, oh, look over your notes or ask someone else. So, I think creating that atmosphere that it's okay to ask questions, it should be able to help those shy students on asking for help when they need help. (Poncho)

Studies have shown that more collaboration to more learning (Ladson-Billings, 1995; Gay, 2002; Morrison et al., 2008). In my teaching, I worked to be receptive to student questions. I extensively supported collaborative learning and interactions in class. Student voices spoke of the instructor's qualities and its impact on their learning.

\section{Points of connection - CRP: Classroom Environment/Community Building}

Out of twelve students, nine students reported appreciated aspects of the class that were coded as "welcoming classroom environment." Three students did not talk about it 
at all. In the exit ticket, out of seventy-five students present, seven students did not respond, two students named classroom environment, which helped them the most in their engagement. The rest of the students did not name this aspect at all. Although students' comments were not specific to stoichiometry, they were talking at a time when stoichiometric topics were being studied in class.

I tried to make a classroom environment welcoming for students by promoting their engagement in class. Isabel approached me for my help in organizing study groups for students to study outside the class. At her request, I interacted with all students and advised them to write their names on board and days and timings they were available to meet in the STEM center. This activity gave them the opportunity to coordinate with each other and form study groups. In the following quote, Poncho valued my efforts by taking some of the class time to organize study groups for students to study outside the class.

I feel the teacher does help on making a community, was taking the time from class and setting up study groups or not even setting them up, just people writing their names on what time they're going to be at the STEM center. That way, I would feel more comfortable in going, just knowing that other people would be there from my class. (Poncho)

Student-to-student interactions can lead to community building (Ladson-Billings, 1995). In the following quote, Bob was appreciative of my classroom environment, 
where students might not know each other. However, they had built a community, and they supported each other in learning. Bob compared my teaching practices to the classes taught by traditional pedagogy. He felt that the one-way transfer of information from instructor to students could get overwhelming.

The classroom environment we have now is pretty good. We are all pretty friendly. Even though if you don't know the names of each other, we all are pretty nice to each other. We always try to help each other. And we can definitely see that we're focused. Not having to focus for an hour and a half straight of the lecture is really nice, and when there are classes like that, your brain melts after a while. (Bob)

Jesus added that a communal environment made students comfortable enough to reach out to anyone in class for support. He said, "We're all very cordial. We all strive for higher goals." This implied Jesus's belief that students had developed a sense of belonging to the classroom. They were motivated and cared for each other's learning. One of the following quotes in the exit ticket implied that students were freely engaging in discussions and that the classroom environment was inviting to them.

The thing I liked the most about the lecture today is how comfortable the dialogic pedagogy method makes me so that I can ask a question and be engaged in the class. 
My classroom looked noisy, where students talked to one another. I intentionally promoted student-to-student interactions so that students trusted and supported each other. Students' comments showed that they had formed a bond with each other, built a community, and did not hesitate to approach their peers for help. I felt validated that my efforts in creating a welcoming classroom environment were productive, and students appreciated it.

\section{Points of connection - ALS: Think-Pair-Share}

Out of twelve students interviewed, only Bob and Isabel mentioned about the impact of TPS on their learning. Their comments were not specific to stoichiometry, but they came up in the interview on the days I was teaching stoichiometry in class. The rest of the students did not mention it at all. For the exit tickets, seventy-five students were present; seven did not respond, seven students named TPS as the most effective strategy in engaging them in class. The rest did not name this strategy at all. In the following quote, Bob appreciated the TPS strategy since it kept him focused, and it supported their learning when they constructed new knowledge together.

When you work with your classmates next to you, it helps a lot because you can work together and figure it out as a lot more, you go a lot quicker because of just two of you. You're not worried about the whole class understanding. So, think-pair-share for me is really helpful. (Bob) 
I could infer from the following anonymous quote in the exit ticket that students appreciated the time for individual thinking, followed by paring up with peers and discussion to elucidate deeper understanding: "What helped the most during the lecture today was when you allowed us time to think-pair-share, I started to understand some topics."

I introduced TPS to students on the first day of the class, and I enforced it in every lecture. Since most of the students did not mention TPS in interview and exit tickets, it makes me think that if my practices were effective enough in promoting active learning in class.

\section{Points of connection - ALS: Study Groups}

Out of twelve students interviewed, six students were proponents of group study. Other students neither supported it nor challenged it. Their conversations were not specific to stoichiometry. However, the interview was being conducted on days we were covering stoichiometry in class. In exit tickets, the topic of study groups did not come up at all. I could assume that the exit tickets were collected at the end of the lecture, where students collaborated using TPS strategy. In contrast, the interviews were held in the lab, where students learned together in groups of $4-6$ people. Therefore, I presumed that the group study might be fresh in their mind when I was interviewing them.

Isabel and Alice appreciated group study. In the following quote, Alice believed that when she worked on the problem, she was not confident in her learning. Alice checked with multiple peers for the solution. Finally, when all came to a consensus, it made her feel confident in her learning. However, Alice's comment led me to think that 
she was using group study as a collaborative learning aspect of CRP. I wished I could have asked her follow-up questions to know if she was actively constructing new knowledge when working in groups.

It's cool because sometimes I'll get an answer. What you know will be working on some new material, and I'll get an answer, and I'll be like, Okay, I'm pretty sure this is it. I'm not sure; I'm not confident in it because it's the first time we've done it, and so then I go to my neighbor, and then I go to my other neighbor, and then I go to my other neighbor, and we all got the same answer. So then, interacting with other people, makes me more confident, even though I kind of thought, I was pretty sure this is right, but I'm not positive, but then talking to other people makes me more confident in what I'm doing. (Alice)

I observed that students were becoming proponents of group study. They not only embraced group study in chemistry, but they also extended this group learning to other courses. It gave me validation when students informed me that they made strong connections with their groups, and they decided to take the same classes next semester so that they could study together.

In summary, the points of connection were student appreciation for certain teaching practices. The examples for such teaching practices were instructor qualities, classroom environment/community building, think-pair-share, and group study. In 
contrast, the points of resistance were the student pushback against specific teaching practices and their preference for traditional methods. The examples of points of resistance were the students' disliking for the use of multiple relatable examples and students' inclination for the use of practice/worksheet/repetition, online resources, lecture slides/YouTube videos, and study guide/practice test. Now I will describe the points of resistance in the following section.

\section{Points of resistance - CRP: Relatable Examples}

Relatable Examples. Relatable examples were those examples in which students could think about their familiar experiences and connect them to science concepts. In the focus group, when I asked students for their feedback on the use of relatable examples to explain the complex concept of mole, I met with resistance from a majority of participants. Students reported that they did not understand the idea of a mole using relatable examples, and they learned it by watching multiple YouTube videos. Alice reported, "Honestly, I'm not sure if there's a way to really connect it to your daily life. I think because it's just such a foreign concept, you just have to know." This implied that she believed that the mole concept was such as abstract concept that it could not be related to familiar experiences for better understanding. In that case, I could infer that she found it necessary to memorize the concept and might not prioritize full conceptual understanding.

Shantal preferred traditional teaching as she felt that relating the mole concept to real-life confused her. She watched YouTube videos to search for definitions to get 
herself prepared for the quiz. For her, the definitions would have been better than using the relatable examples.

After receiving strong pushback from every direction in the interview, I asked my interviewees if they had to explain the concept of the mole to the class, how would they approach the problem? They all gravitated towards traditional teaching with shallow learning. Chalino suggested that instead of relating the mole concept to goody bags, I should have shown them the calculations and enforced it with repetition, as evident from her following quote.

How to cross out the common moles to get the grams or the crossing out the grams to get moles. I think that now, over and over again. It's not necessarily about how good you explain it. To repeat it over and over again, and that's how I would teach it. (Chalino)

Multiple Relatable Examples. Out of twelve students in the focus group, two students preferred one simple example over various relatable examples, and the rest of the students did not talk about it. Poncho and Ana wanted me to explain the concept in mathematical terms instead of using relatable examples. In the following comment, Ana felt that she got distracted when I introduced additional examples to explain the concept. She said, "I agree with Poncho. I need kind of one simple example because I feel when it goes into a few other examples, I either just get lost or get distracted." It made me wonder if she was just taking the information, I was providing instead of actively 
engaging in class. This may well reflect a disconnect between what students experienced in my class versus what they expected of instruction in a science classroom.

As I was listening to students' resistance to the use of relatable examples to explain the mole concept, my heart was sinking. I started self-doubting. I wrote in my journal:

Oh, God! I am not good enough. After implementing CRP and ALS and caring for my students and their learning, students are not satisfied with their learning. I am not doing a good job supporting students.

Now, when I have time to reflect on my pedagogy and students' feedback, I started to think that I was leading students to an unfamiliar territory of active learning, and they were resisting and pushing me back to their familiar area of conventional learning. Besides, the example, I identified as "relatable" might not be sufficient to explain the mole concept. Students could relate the distribution of items in the goody bag to atoms or molecules. However, the relating of exponential quantities and their interconnections with familiar experiences was difficult.

\section{Points of resistance - Practice/Worksheet/Repetition}

Out of the twelve students interviewed, all of them wanted more problems for practice and repetition. Some students treated worksheets as a source of practice, which did not constitute active learning. Repetition and practice represented traditional pedagogy, where students were recipients of the information. Out of seventy-five 
students present for exit tickets, seven did not respond, and four students named repetition and practice to be the most useful aspects in their engagement. In the following quote, Ana wanted a printed copy of the worksheet so that she could practice at home, which implied that she continued to use the conventional method of repetition for shallow learning.

"I think that the instructor should provide a worksheet that the people can take home and work on later on. So, you could get additional practice.” (Ana)

Chalino liked redoing the examples for practice, and she considered worksheet as a guide for the upcoming quiz. Jesus recommended that the instructor should reinforce the idea of practicing for students to do better in class. Students' inclination towards repetition and practice as a mode of learning showed their resistance towards active learning practices.

Big Tuna preferred to work on a worksheet with a peer because he assumed that he was unable to use critical thinking skills, and as a result, he was unable to contribute to the group discussion. He believed that he needed a peer to guide him with problemsolving skills when working on a worksheet. I could infer that he expected his peers to do the same as an instructor would do when teaching with conventional methods.

I posted worksheets and their answer keys on Canvas for convenience. I advised students that it was a resource for them to work in groups outside class time. Each of them should contribute to group discussions to synthesize new knowledge from prior 
information. While working on worksheets, I did not anticipate that they would have the answer key in front of them. The answer key was for reference only, and I intended it to be used as a last resort. When I was listening to students' comments, I felt that they were using worksheets and answer keys for practice and repetition, not in the way I had intended, but likely in the way they had learned to use such tools in the prior school experience. It seemed as if students had not yet embraced my teaching practices of active learning beyond classroom time.

\section{Points of resistance - Online Resources}

All students in the focus group wanted me to upload resources online, which included lecture slides, YouTube videos, study guides, and practice tests. Such online resources do not constitute active learning since it does not involve actively constructing new knowledge. Not a single student remained neutral or challenged the idea of posting resources online. However, in the exit tickets, out of seventy-five students present, only three students considered the study guide as the most effective strategy for their engagement. It was a stark difference in student responses in interview versus exit tickets. The lecture was concentrated on active learning strategies within the framework of CRP. Since exit tickets were collected right at the end of the lecture, I could infer that at the time of exit ticket collection, students' focus was on learning new material, and they were not necessarily thinking about the online resources. Because of how exit tickets were structured, I cannot conclude what students in the class as a whole thought of the online resources or how/ if they made use of them. 
Students in the focus group talked extensively about a variety of supports posted online and actively requested additional resources be added. Their discussion of the resources and how they used them indicates a mismatch between the active learning stance I tried to grow in my class and the ways in which students studied and engaged in learning outside of class time.

Lecture Slides/YouTube videos. Students in the focus group indicated that they wanted me to provide lecture notes online. Sammy believed that it would help avoid confusion during the lecture. Isabel considered herself not a good note-taker, but she noted that online lecture notes could help her to catch up with the information she missed in class. Bob wanted it for convenience so that he could avoid taking notes in class. Posting lecture slides and taking notes in the class were all references to the traditional pedagogy, where the instructor transferred the knowledge to students. On students' requests, I started posting my lecture slides and YouTube videos on Canvas, which students reported loving. Shantal's following quote described her liking for the video. I could infer that she watched the video as she listened to a traditional lecture without challenging it.

Because the videos that you're posting are very detailed, and they break things down to multiple steps. And I can pause the video and then copy the equation and then try to figure out by myself and then play it to see what I got what he got. It makes me see if I'm doing that right or not. And 
then he explains it, why it is that. So that way, I know that if I got the right answer wrong and why. (Shantal)

Reflecting on my efforts to accommodate students' requests, I question myself why I succumbed to students' gravitation towards online resources. Students were asking for online resources believing it to be helpful in their learning. I cared for my student learning, and therefore, I intended to support students by providing them resources, online, as they requested. However, it is important to note that it is understandable students would ask for and use resources in the ways they have used them in other settings, particularly if these resources matched better with their existing ideas of what it means to learn science effectively.

Study Guide/Practice Test. Previously, I had been posting a general study guide before exams, which included all the topics required for our curriculum. At the students' request, once I posted a study guide that covered specific topics as were necessary for quiz preparation, and they loved it. Students appreciated my posting of such a study guide since it helped him narrow down the topics that he needed to study for the quiz. I could infer that their focus was to pass the exam instead of having a deeper understanding of the concepts.

Some students asked for additional modifications to the study guide. Ana suggested that a study guide should have the percentage assigned to each topic. She believed that a general study guide did not help her with passing the exam. Poncho recommended adding example questions to such a study guide. Shantal wanted a practice 
test, where students could see the topics and questions they were tested on. Sammy, in the following quote, suggested that the study guide should be a replica of the quiz. She gave examples of her courses $\mathrm{X}$ and $\mathrm{Y}$ to prove the impact of the replica of the quiz on her academic success. I named the courses X and Y to keep them anonymous.

Teachers should create a study guide that looks almost similar to a test because I know in some of my $(\mathrm{X})$ classes, there have been many times where a teacher gives us the study guide, and it looks nothing like the test and then she gets upset when every student fails. In my last (Y) class, my teacher would give us a study guide to look exactly like the test, and every time, every student passed. (Sammy)

I could infer from student's persuasion of posting study guides with specific topics, percentages, sample questions, a replica of the quiz, that they believed that the key to passing the class was rote memorization, not continued engagement in active learning. I firmly believed that such accommodations would not support in-depth student learning. As a result, I did not yield to such a recommendation. However, at some point, I empathized with students that they were extremely stressed, and they needed direction for a focused study. I felt I needed to be flexible and support them. Therefore, I posted the study guide with specific topics to help students relieve their stress. I also posted my lecture slides and YouTube videos. As I am reflecting on my teaching practices, I feel that I yielded to students demand of traditional pedagogy. I inferred that students were 
pushing me back towards the conventional way of teaching since they were used to that way. They felt comfortable with the one-way transaction of knowledge.

\section{Points of Uncertainty}

Students directly reported benefitting from some of the changes I made to my practice, and they actively resisted others by advocating for traditional resources to support memorization and replication of answers. On the other hand, there were some components of culturally responsive pedagogy that I anticipated would matter a lot that did not come up at all in student feedback, either positive or negative. For example, when I was analyzing student responses, I anticipated that a "trust" aspect of instructor qualities (CRP) would be significant in students' minds. Witt et al. (2014) emphasized that when students perceived their instructor as trustworthy, it increased their motivation to succeed. Somehow, students did not bring up the trusting relationship between the instructor and them and its impact on their learning. With a lack of supporting data, I could only infer that students considered other practices as more important in influencing their learning. It could also be that students did not name this as a supporting factor because they took it for granted.

Alternately, I expected that the instructor quality respecting students (CRP) would come up in the data, but I did not expect that it would come up with intense responses. Students were adamant that it affects their academic achievement. Kezar and Maxey (2014) posited when the instructor showed their care by respecting students; it increased their willingness to engage. Probably, I incorrectly assumed that it was a common practice for instructors to respect students, and there was nothing new about it. However, 
student comments strongly indicated the essence of traditional pedagogy, where instructors did not respect students. Only two students brought this up, so the finding might be idiosyncratic, but for the two students who did talk about this in the focus group, they firmly emphasized that it had an impact on their academic achievement.

ALS: Think-Pair-Share. While I considered the incorporation of TPS was a critical change to my practice, most students did not name it as particularly positive or negative to their learning. From their lack of responses, it was uncertain if students considered the impact of TPS on their learning. However, students spoke highly of the interactions with neighbors in class, where they collaborated to learn together. I assume that students might have considered TPS the same as interactions with neighbors.

ALS: Group Study. Students in the exit tickets did not mention group study at all, whereas, they spoke of it highly in the interviews. It was not surprising to me since exit tickets were collected immediately after the lecture. I imagined that student minds were occupied in class with an understanding of the concepts using interactive strategies, such as collaborative learning, TPS, and relatable examples. I inferred the strategy of group study was not on their mind when they were commenting on exit tickets. With the lack of data in reflective exit tickets, it was uncertain that group study had positively impacted their learning. At the same time, students were highly appreciative of interactive learning during interviews. I assume that students might have considered group study as interactive learning. 
The overall outcome of CRP and ALS enhanced course

While students did not always name specific strategies as particularly helpful to them, the actual results show that this version of the class worked incredibly well, as seen in the outcome data (see Table 3) as well as in the students' feedback in the pretest and posttest survey (see Table 4).

Table 3

The average pass rate in my classes

\begin{tabular}{|c|c|c|c|}
\hline$\underline{\text { Years }}$ & $\underline{\text { Semester }}$ & $\underline{\text { Pass Rate }}$ & Average \\
\hline 1 & Spring13 & $90 \%$ & $83 \%$ \\
\hline 2 & Spring14 & $78 \%$ & \\
\hline 3 & Spring16 & $76 \%$ & \\
\hline 4 & Spring17 & $85 \%$ & \\
\hline 5 & Spring18 & $88 \%$ & \\
\hline 6 & Spring19 & $80 \%$ & \\
\hline 1 & Summer13 & $87 \%$ & $90 \%$ \\
\hline 2 & Summer14 & $98 \%$ & \\
\hline 3 & Summer15 & $84 \%$ & \\
\hline 4 & Summer16 & $93 \%$ & \\
\hline 5 & Summer17 & $77 \%$ & \\
\hline 6 & Summer 18 & $93 \%$ & \\
\hline 7 & Summer19 & $96 \%$ & \\
\hline
\end{tabular}


The average pass rate in the summer semesters is usually higher than that of the fall or spring semester (Table 3). Students getting grades A, B, or C, are considered passing the class. The pass rate of students enrolled in spring19 in my class was $80 \%$, which was lower than the previous year. The most probable explanation was that it was the first time that students from the First-Year Experience (FYE) were enrolled in this section. The students in FYE needed extra support to succeed in this Chemistry class. This change in the composition of the class from previous years makes it impossible to determine positive or negative impact of the CRP/ALS strategies on student success.

The summer cohorts consist of Allied Health majors and the composition has remained similar across years. The $96 \%$ pass rate in summer 19 was higher than that of 93\% summer18. A $96 \%$ pass rate in a five-week summer semester indicates that the class did not serve as a gatekeeper for students pursuing higher education in STEM in a community college. These results indicate that this class has been largely effective for students over the years, but that CRP and ALS infused version was particularly impactful for the summer group.

The Likert scale data in pretest and posttest surveys show that $43 \%$ of students appreciated Chemistry in their daily lives when they came to my class for the first time. Their appreciation for Chemistry increased to $78 \%$ on the last day of the class (Table 4). Similarly, $21 \%$ of students felt strongly about their potential to succeed on the first day of the class, which increased to $90 \%$ by the last day of the class (Table 4 ). 
Table 4

Likert scale data on Student Beliefs: Pretest vs. Posttest

$\%$ responses of students, who agree or strongly agree with their belief, in the Likert

Scale in Spring and Summer semesters (Likert Scale Pretest was not given in Spring)

\begin{tabular}{ccc}
\hline$\underline{\text { Belief }}$ & pretest & posttest \\
\hline I appreciate Chemistry in my daily life & $43 \%$ & $78 \%$ \\
I identify myself as a science student & $70 \%$ & $63 \%$ \\
\hline Coming to this class, I feel strongly about my potential for success & $21 \%$ & \\
\hline After taking this class, I feel strongly about my potential for success & & $90 \%$ \\
\hline High School Chemistry has prepared me well for this class & $85 \%$ & \\
\hline This class has prepared me well for the next class & & $79 \%$ \\
\hline
\end{tabular}

\section{Summary}

Community colleges are designed to provide access to affordable higher learning for underserved student populations (Boggs, 2004). Community college instructors are usually afforded the flexibility to create their own lessons and implement their own teaching practices in the classroom. Students enter community college classrooms as diverse learners, and with a distinct level of maturity (Bragg, 2001). Instructors often teach as they were taught, using top-down instruction, perceiving themselves as information holders in charge of transferring. Because this often matches students' prior experiences in school, students themselves may not identify this as problematic, and may actually appear to prefer it, as shown in some of the data analyzed here. Alternatively, 
the instructors who respect students and share the classroom with them for discussions and ideas exercise the responsive pedagogical approaches. While research shows the long-term benefits to learning and retention with such an approach (Ladson-Billings, 1995), actually implementing such changes when students are used to a more traditional style of teaching can create resistance to new approaches.

As a community college instructor, I decided to reflect on my teaching practices and students' feedback in response to those practices. My growth in understanding my positionality with the content, and to the student has inspired me for this self-study. I changed my practices with students' participation and in-depth learning in mind. Findings from the current study suggest instructor qualities such as respectfulness, intentional interactions, receptiveness to students, and promoting collaborative learning influence positively students' perception of their learning. Findings from the present study also indicate that a welcoming classroom environment invites students to build community. Findings regarding specific active learning strategies were more inconclusive in this study and may require additional data and analysis to fully understand.

In the next chapter, I will present the implications for the significance of findings as they relate to the transition to active learning away from traditional pedagogy, followed by recommendations for action and further study. 


\section{Chapter Five: Discussion and Recommendations}

Community college instructors are essential toward creating welcoming classroom learning environments for students. Self-reflection and continuous learning are critical elements community college instructors could utilize to help create welcoming classroom learning environments. I used each of these elements for this selfstudy. Self-reflection was used to examine my previous teaching approaches, as well as to examine where and how I was growing as an instructor with my students. Continuous learning happened throughout the study. Continuous learning occurred through the regular reviewing of the theoretical and empirical literature, individual and group processing opportunities, and in-depth focused discussions with several instructors. Selfreflection and continuous learning contributed to the intentionality I developed and with the hopes of enhancing my teaching practices for the students that I serve.

The following section will begin with the interpretation of the findings. The next section will focus on the implications in terms of educational leadership, followed by the implications in terms of equity.

\section{Interpretation of Findings}

This self-study was designed for two reasons. The first reason was that I wanted to enhance my teaching practices in a STEM introductory course at a community college. The second reason was the importance of instructors taking the necessary steps to create a welcoming classroom environment for all students. I used certain aspects of culturally responsive pedagogy and specific active learning strategies to create a welcoming 
environment that would ultimately contribute to the enhancement of student learning in the STEM classroom. Pretest and posttest surveys, focus group interviews, reflective exit tickets, and reflective field notes were used as sources of data collection. A total of ninety-two students were enrolled during the time of the study. All ninety-two students completed the pretest, the posttest, as well as exit tickets in the spring and summer semesters of the year 2019. Eighteen students participated in the focus group portion of the study. For the current study, I utilized the following culturally responsive practices (CRP): instructor qualities, use of relatable examples, and creating a welcoming classroom environment. Also, I utilized the following active learning strategies (ALS): think-pair-share and group study.

Findings from the current study suggest that students are more likely to participate when STEM instructors implement student-centered strategies such as collaborative learning, think-pair-share, etc. Although students did not explicitly name studentcentered strategies as something that enhanced their engagement, I observed a higher level of student participation in class. For example, the level of student interaction increased when they utilized the think-pair-share strategy. Another example, I witnessed an increase in students' discussions on trying to understand the concepts that were presented, as well as to problem-solve. It made a classroom noisy, a contrast to traditional learning, where students listened to the lecture quietly. Gasiewski et al. (2012) employed a mixed-method approach to study the relationship between student engagement and introductory science instruction. The researchers found students were more engaged when the instructor created a welcoming environment. 
Findings from the current study illustrate that a combination of active learning strategies can lead to higher academic achievement. Although I had anticipated that students would name a specific strategy that had a profound effect on their learning, relatively few students directly reflected on a specific strategy that was critical to their learning. Based on my findings, it can be argued that there is not one specific strategy that works best. However, more research is needed to identify the significance of a multi-strategy approach to STEM. The overall response to the STEM courses that I instructed was positive. I interpret that for most of the participating students, the combination of CRP and ALS had a positive influence on their higher academic achievement. Similar to Tanner (2013), the current study employed teaching strategies designed to promote student engagement and classroom equity through think-pair-share, observing student participation, integrating relevant examples, work in small groups, and establishing a classroom community. Each of these strategies was beneficial toward creating a welcoming classroom environment. Therefore, STEM instructors in community colleges should continue to implement a combination of strategies, such as collaborative learning, think-pair-share, and group study in the classroom.

Findings from the current study imply STEM instructors, who implement studentcentered strategies may face resistance from students in terms of students' disliking of such strategies. Specifically, in my self-study, many students actively resisted a more conceptual approach to learning. For example, students did not like the use of relatable examples to explain certain concepts, such as using "dozen" to describe the "mole" concept. Instead, students requested more rote learning practices, such as videos, answer 
keys, etc., which do not require active learning. It implies that students and instructors often revert to the way they are used to learning, believing it to be effective. Brownell and Tanner (2012) emphasized faculty who had been teaching with traditional pedagogy might be resistant to change, citing lack of time as one of the barriers. In traditional classrooms, students are taught to absorb pre-packaged information presented by their teachers using traditional pedagogy (Brownell \& Tanner, 2012). Redman (2013) presented a case study that integrated educational pedagogy, behavior change, and sustainability competencies. The researcher found "convenience" as the most significant barrier to change. Therefore, it is not surprising that instructors and teachers tend to revert to traditional pedagogy because they are used to such practices. It is worth noting that in my self-study, students did not push back on everything. However, they did push back on the strategies that took them out of their comfort zone (Redman 2013). Looking ahead, I will be mindful to differentiate traditional pedagogy from active learning in class and stay consistent with active learning strategies. The findings also suggest a need for more research on how to support students in adapting to new ways of learning.

\section{Implications in terms of Educational Leadership theory and practice}

\section{Recommendation for unified CRP and ALS praxis}

This self-study illustrated how incorporating the cyclical process of applying theory through instructional practice, and reflecting on the process, the impact, and the outcomes can help instructors in community college STEM classrooms have a positive effect on students' social and academic outcomes. The cyclical process mentioned above 
is referred to as praxis. Scholars have emphasized the significance of why educators should use praxis as a way to approach implementing instruction (Torres \& Mercado, 2004; Brandenburg \& Gervasoni, 2012). Important to note, incorporating praxis can help the instructor to deter from utilizing a traditional top-down approach of implementing instruction, and instead learn with students through dialogue centered on real-world scenarios. Incorporating real-world scenarios and utilizing a didactic instructional approach with students to pose real-world problems is one way to promote social engagement while making connections between academic concepts and real-life situations.

Praxis helped me see the importance of taking a more responsive pedagogical approach to teaching. Findings from the current study helped illustrate how a community college STEM instructor can reflect on their quality of instruction, intentionally create welcoming classroom environments, and utilize relatable examples through student group activities, and think-pair-share. In the current study, I utilized certain elements from the CRP framework, and certain instructional strategies of ALS to increase students' interaction during class, and students' academic outcomes for the course overall. I reflected on my instructional approach, my intent, my internal (mental and emotional) processes, and the impact through students' feedback. This reflection process helped me to enhance my awareness of what instructional approaches and strategies were working and were NOT working for students. I adjusted my approach, and as a result, students were interactive during class. Students also improved their academic outcomes. 
Therefore, I recommend community college STEM instructors incorporating the elements of CRP in teaching pedagogy.

There is existing literature that emphasizes the importance of Culturally Responsive Pedagogy (CRP) on student learning (Ladson-Billings, 1995). Likewise, there is a growing body of literature that signifies the importance of utilizing Active Learning Strategies (ALS) toward student academic success (Lom, 2012; Freeman et al., 2014; Auerbach \& Andrews, 2018). While these theories have previously been implemented in silos, this study attempted to unify the two concepts utilizing a praxis frame of reference. Students in the current study demonstrated how they could be responsive to their own learning when they attempted to make explicit connections of complex content topics to their real-world lived experiences. Also, findings from the current study suggest that elements of ALS such as think-pair-share, and group study were effective. It is important to note, think-pair-share, and group study occurred when the three identified elements of CRP were already in place.

\section{Implications for Instructor}

This self-study allowed me to make connections between self-reflection and continuous learning. The self-study is a means to grow personally and professionally. When I started my teaching journey, I primarily concentrated on the content. As time progressed, my extensive teaching experience and this doctoral program allowed me to focus on student experiences and their strengths. The findings in this study, as a result of the implementation of various instructional strategies, supported my growth as an instructor in understanding student learning. Humerick (2002) claimed that self-study 
makes us aware of our instructional practices in the classroom and their influence on student learning. Now, I will talk about self-reflection and continuous learning for the implications for the instructor.

Self-Reflection. Self-reflection is the examination of their own teaching practices in which instructors are engaged (Zeichner \& Liston, 2013). Self-reflection is often used to understand the depth of the problem and explore new opportunities to improve its own practices (Dewey, 1933). In this study, I utilized self-reflection to improve my instructional approach. A close analysis of students' feedback resulted in a shift in my instructional approach and my demeanor when interacting with students (MegowanRomanowicz, 2010).

I have become more compassionate towards students after a close examination of student feedback and my own thoughts and feelings about how I was instructing. Selfreflection has helped me understand, each students' learning experience will differ with how I implement an instructional approach, as well as concerning my demeanor. Selfreflection helped me pay closer attention to the classroom environment.

I became a better observer and more reflective in my teaching. I need to observe students' participation and purposely to listen to students' feedback (Reznitskaya, \& Gregory, 2013). I used moments of self-reflection to think about other pedagogical ways to help students engage, how to increase my interactions with students, and how to increase their interactions with each other. I regularly reflected on what strategies I should and should not utilize so that abstract concept would be understandable for students. I was also proactive in thinking about how I can support students in promoting 
their critical thinking skills. As educational leaders, we need to think strategically and proactively about trying new instructional approaches to figure out what teaching strategies work for students. It is made clear from the below excerpt from one of my field notes:

Earlier, when the students kept on repeating the same mistake, I used to get frustrated with the assumption that they were not investing time in studying the subject. Currently, I am working on improving my pedagogy by making a conscious effort not to get disappointed at students. Instead, I started asking for feedback from students. To my surprise, I found that students were studying but had a partial understanding of the concept. Besides, I realized that the new focus on students' learning brought patience and calmness in my attitude without making an extra effort. With this awareness, I started going over the missing link in their learning process and, therefore, bridging the learning gap in their knowledge.

The above quote helps to illustrate that I am shifting my pedagogical approach from the practice of blaming students for the existing disproportionate academic outcomes where the broader educational system has failed them. Now, I seek student feedback for the support I should provide to them to help them succeed. Student feedback resulted in identifying the areas where I could support them. I learned from my self-reflection that my earlier reaction was shutting down students' learning. I have also 
come to realize my new experiences with students as they learn and grow as scholars have influenced a positive change in my demeanor. The self-reflection led to my critical thinking efforts in bringing educational change in my teaching practices.

Need to develop all aspects of CRP. For this self-study, I integrated two of the three tenets of CRP. The first tenet is that all students experience academic success, and the second tenet is that all students demonstrate cultural competence (Ladson-Billings, 1995, p. 474). While I have gained a better understanding of the two selected tenets through this self-study, I am also fully aware of the need to further develop the third tenet of CRP. The third tenet and arguably, the most important is for students to develop critical consciousness (Ladson-Billings). It is important that students develop critical consciousness. Critical consciousness helps students to understand differences and recognize injustice (Reed et al., 1997). Classroom discussions, instructional tasks, group activities, and think-pair-shares can involve opportunities for students to develop their critical consciousness. In fact, these could also be opportunities for me to learn with students about how personal and structural barriers are impeding them from succeeding. Individual, small group, and whole-group reflections would help with the enrichment of my, and the students' critical consciousness. These reflections can be centered on the abstract of "educational experiences" in relation to individual and shared educational experiences within a given social and/or academic setting. The central theme that did not occur in this study is critical consciousness. That theme within this context of the study would have been to question the power dynamics in a traditional classroom (Pitner \& Sakamoto, 2005). A strength of critical consciousness is to be continuously 
aware of power differences. Critical consciousness is an on-going process of acknowledging existing inequities, discussing the inequities, and taking action to address the inequities. Here, I acknowledge that I have more work to do in relation to supporting students in developing critical consciousness.

Need to manage student resistance. The findings of the current study suggest that students can be resistant to some aspects of CRP and ALS. For instance, students resisted my attempt to explain the mole concept, which was unfamiliar to students. Students expressed that the examples I provided did not work, and as a result, they requested YouTube videos, definitions, and mathematical computations. Instructors are asking students to display their vulnerability. As a result, the process of learning an unfamiliar concept through new instructional practices is difficult. For instance, I asked students to engage with peers in constructing new knowledge. Students felt vulnerable when asked to engage with peers in active learning. Scholars suggest that student resistance to the unfamiliar concepts and new instructional approaches is a natural process (Felder \& Brent, 1996; Fletcher \& Bullock, 2012; Vanassche \& Kelchtermans, 2016). I discovered that I needed to improve my ways of acknowledging student resistance in a way that supported their learning.

Instructors can engage with student resistance in a variety of ways. The first step instructors can take to engage with student resistance is to self-reflect on how their intentionality impacts student social, emotional, and educational learning experiences (Vanassche \& Kelchtermans, 2016). For instance, I reflected on how my intentions to implement new instructional strategies impacted students and influenced student 
resistance. Subsequently, I talked with colleagues and reviewed evidence-based studies as a part of my self-reflection. This process helped me better understand why students resisted.

Torres and Mercado (2004) recommend instructors engage in verbal processing protocols through peer dialogues as a particular strategy to develop ways instructors can handle student resistance. The researchers suggested instructors not to react to student resistance immediately. When instructors tend to seek an immediate solution to a situation, it may result in frustration and an urge to give up (Fletcher \& Bullock, 2012). In addition to instructors learning student engagement approaches through peer dialogues with their colleagues, they can also receive emotional support to help deal with various challenges they experience. Therefore, I recommend self-reflection and share the experiences with peer faculty to manage resistance to change.

Need to understand cultural diversity for active learning $(A L)$. Active learning allows students to collaborate in constructing new knowledge. Students work together in small groups or with peers using a think-pair-share strategy. The collaboration is essential because it engages students "in a process of intellectual negotiation and collective decision-making” (Trimbur, 1989, p. 602). When students collaborate, they build a community wherein students take responsibility for each other's learning instead of competing and make collective decisions. Cultural values define communication and decision-making processes and therefore shapes each student's interactions during collaboration (Carr, 2002). I ask students to collaborate in class, but some students do not seem comfortable collaborating. At that time, I approach them and try to understand 
why they do not feel comfortable engaging in collaboration. I try to understand the communication patterns of their culture and what are the ways students engage in active learning in terms of their cultural experiences. Then, I share with students my cultural experiences with collaboration and explain that collaboration helps in the construction of new knowledge and deeper learning. At that point, while being sensitive to the student cultural perspective, I try a few strategies to help students feel more comfortable with collaboration. One strategy is that I ask students to group with peers, whom they feel most comfortable talking to. Another way is that I ask students if I can be their partner in the group until the students feel comfortable in collaborating. The third strategy is that I sit down with the student privately and practice where both students and I learn collaboratively. As an instructor, I intend to understand student cultural experiences so that I can better support student learning by stimulating collaboration.

Active learning allows students to engage in deeper learning by connecting the foreign concept to their familiar experiences. When students link the unfamiliar concept to their familiar experiences, it helps them better understand the concept. Students share the different ways of making connections, which helps in the understanding of the ideas and each other's cultural experiences. However, some students are unable to find a connection with some concepts. I approach students individually and try to understand why students seem to have trouble finding a link to ideas on their own and if it is related to their cultural perspective of learning. I probe them further to understand which of the connections students find most interesting that their peers made. Then I share my cultural experience with students and explain that failure to find the connection inhibits 
student learning. At that point, I work with students one-on-one to help them link concepts to their experiences. In the process, students and I share something about each other's culture. Having open communication and supporting students in learning to make connections is a way of communicating about each other's culture, which culminates in a deeper understanding of the chemistry concepts.

Active learning involves students asking questions in class to construct new knowledge. Students do not take knowledge "as given" by the instructor. Asking questions stimulates student thought processes, and it promotes deeper learning. Communication styles mark cultural values. If the culture defines sitting quietly and passively receiving information in class a sign of respect to the instructor, the student most likely will not ask a question in class. The instructor can falsely assume that the student is not trying to learn actively. During my lecture, I consistently encourage students to ask questions. Despite this, some students do not ask questions in class. I approach students and have a conversation with them privately and try to understand why they do not seem comfortable asking questions in class and whether it was related to their cultural experiences. I share my cultural experiences with them. Asking questions in class is vital because it stimulates new ideas for synthesizing new knowledge. Finally, I extend my support by asking them how I can make them feel more comfortable asking questions in class. My conversation with students helps me understand their cultural perspective on asking questions in class instead of blaming students for not asking a question. I acknowledge that the changes in my pedagogy are incremental and more understanding of students' cultural identities is needed to support their cultural 
competence (Ladson-Billings, 1995) fully. Despite having limited knowledge of students' cultural identities, I treated students with respect and created a learning environment that welcomed differences.

Continuous Learning. A second implication for the instructor is continuous learning. The self-study is a part of continuous learning. The thinking of teaching practices, their implementation, student responses, the findings of student achievement, their correlation with the literature, and adjustment of strategies is an iterative process. The intention of the instructor to learn continuously is a step closer to bringing educational reform in a classroom. I tried different approaches. I talked to my colleagues about the practices they implemented in their classrooms. I also sat through other STEM classes that were instructed by my colleagues, which some were considered to be the best among the student community for their classroom practices. I wrote my field notes about my experiences in these classroom observations. My experiences in my community college classroom, on-going dialogue with my colleagues, continuing reading theoretical and empirical articles will be the implication for the continuous learning process. Reflecting on my teaching practices provides me a way to identify the problem, seek opportunities, and incorporate different strategies to resolve the issue. Selfreflection is a continuous process and a part of continuous learning. Therefore, the implication for this study is that reflecting through the self-study is one of the ways instructors can learn continuously. 


\section{Implications in terms of Educational Policy Issues}

\section{Professional Development (PD)}

There is a need for the administrative leadership at Progress College to provide opportunities for faculty to address the lack of equity-based professional development (Hudley \& Mallinson, 2017). Equity-based professional development, in this context, is when instructors self-examine the intentionality and impact of their teaching practices on all students. Self-reflection enables the instructor to identify how their social and cultural experiences influence the ways in which they impact student learning. Therefore, I recommend that Progress College administrators provide opportunities to all faculty for equity-based PD.

Self-study is one-way faculty can grow in their personal and professional approach to providing humanizing and equitable learning opportunities to all students (Samaras et al., 2004). The findings in the current study suggest that self-study has the potential for the instructor to understand student learning and to improve teaching practices accordingly. After my doctoral program, I plan to meet with the dean of the science and math department of Progress College to discuss what self-study professional development could look like for STEM instructors. Prior to meeting with the dean, I will review the current study and share my ideas with other STEM instructors from surrounding community colleges. Additionally, I will facilitate workshops that emphasize the importance of self-study. The workshop will also include the "How-To" conduct a self-study as a community college STEM instructor. Faculty who participate in the potential self-study PD would meet once a month to share their intentions, impacts, 
challenges, and successes pertaining to implement new instructional strategies, particularly in relation to help underserved student groups (Gallagher et al., 2011;

Williams \& Ritter, 2010).

\section{Faculty Contract}

According to the faculty contract in Progress College, a new faculty is evaluated over a period of four years, and tenured faculty are evaluated once every three academic years. The evaluation consists of class visits where an administrator or peer instructor observes the teaching. The evaluator also collects students' anonymous feedback on scantrons. However, the questions on scantron do not pertain to the use of an interactive approach in a STEM classroom. I recommend the inclusion of a few questions on the scantron. These questions should be specific to the instructor using interactive strategies in the classroom.

\section{Implications in terms of Educational Equity issues}

\section{Change in instructional pedagogy to address diversity}

The purpose of community colleges is to serve the diverse population of California. Policy changes, such as First-Year Experience (FYE) and AB705, are likely to diversify the student population. These students must enroll in introductory science classes to pursue STEM majors. FYE offers a rigorous science curriculum for first-time college students (Berkeley City College, n.d.). AB 705 requires community colleges to maximize the probability that all students complete transfer-level coursework in English and math within a one-year timeframe (California Community Colleges, 2018). The 
underserved students, such as African American and Latin(x), were previously deprived of opportunities to enroll in science courses. These two particular policies have added diversity to the classroom by providing opportunities to underserved students. As a result of diversity, a continuous change in instructional pedagogy in the introductory science classroom is required to support the academic success of a higher proportion of incoming underserved students. Instructors, who continue to self-reflect, self-examine, and modify their personal and professional approaches can better support student educational experiences and student academic success in community college science courses.

\section{Increased class completion rates in STEM}

The STEM instructors have an opportunity to support students, especially underserved student populations, in their goal of succeeding in challenging courses. Though the pass rates in my "gatekeeper" classes had been high, the findings from chapter 4 show that when specific active learning strategies were integrated into certain culturally responsive practices, it resulted in a higher pass rate of $96 \%$ in the summer semester. Tanner (2013) calls student-centered activities as "equitable teaching strategies" because the implementation of such strategies leads to classroom equity.

A higher pass rate means a higher number of students earning a passing grade; it also implies that students were supported to proceed to STEM-related higher-level courses, specifically in Introductory Chemistry. The potential implications for equity in community colleges are steering of college faculty towards equity-focused teaching, which uses components of CRP and ALS. The aspects of CRP and ALS have benefits of creating a welcoming environment in improving student success. The future study and 
supporting other professors to examine their own practice in their self-study has the potential to increase equity.

\section{Conclusion}

Teaching is a rewarding experience, especially after progressing through their careers when some underserved students visit the STEM instructor and share their experiences of how the instructor's teaching practices had impacted their success in the "gatekeeper" class. Self-study is an intentional way for instructors to examine their own instructional practices and their impact on student achievement. Self-study is a means to a valuable and exciting experience. Through self-reflection, the instructors can continue their quest to bring educational reform by incorporating components of CRP into ALS to prepare students for the rigor of the subject. Being a STEM instructor of a gatekeeper course, I gained from this self-study that a quest for continuous learning begins with student feedback. When I saw the incorporation of specific active learning strategies embedded in culturally responsive teaching practices resulted in higher achievement, it meant an equitable opportunity was provided to underserved student populations to excel. The pass rate of $96 \%$ compared to $93 \%$ in the previous semester contributed to making this course as a "gateway" course for students for higher education in STEM. This selfstudy gave me a glimpse of how instructional leaders can contribute to providing equitable learning opportunities to underserved student populations in the challenging introductory chemistry course. 


\section{References}

AACC (n.d.). Fast Facts 2019. American Association of Community Colleges. https://www.aacc.nche.edu/research-trends/fast-facts/

Aceves, T. C., \& Orosco, M. J. (2014). Culturally responsive teaching. University of Florida. http://ceedar.education.ufl.edu/tools/innovation-configurations/

Adams, T., Robinson, D., Covington, A., \& Talley-Matthews, S. (2017). Fueling the STEMM pipeline: How historically Black colleges and universities improve the presence of African American scholars in STEMM. Journal of Urban Learning, Teaching, and Research, 13, 9-25.

Aldana, U. S. (2014). Moving beyond the college-preparatory high school model to a college-going culture in urban Catholic high schools. Journal of Catholic Education, 17(2), 131-153.

Allen, D., \& Tanner, K. (2005). Infusing active learning into the large-enrollment biology class: seven strategies, from the simple to complex. Cell biology education, 4(4), 262-268.

Auerbach, A. J. J., \& Andrews, T. C. (2018). Pedagogical knowledge for active-learning instruction in large undergraduate biology courses: a large-scale qualitative investigation of instructor thinking. International Journal of STEM Education, 5(19), 1-25.

Ayoade, E. O. (2012). Bridging theory and practice: Application of Constructivist tenets to the teaching of reaction stoichiometry. AFRREV STECH: An International Journal of Science and Technology, 1(1), 144-163. 
Bamiro, A. O. (2015). Effects of guided discovery and think-pair-share strategies on Gsecondary school students' achievement in chemistry. SAGE Open, 5(1), 1-7.

Bataineh, M. Z. (2015). Think-pair-share, co op-co op and traditional learning strategies on undergraduate academic performance. Journal of Educational and Social Research, 5(1), 217-226.

Benham, M. K., \& Clandinin, D. J. (2007). Mo'ōlelo: On culturally relevant story making from an indigenous perspective. In D. Jean Clandinin (Ed.), Handbook of narrative inquiry: Mapping a methodology (pp. 512-533). London: Sage

Berkeley City College. (n.d.). The First Year Experience (FYE) Program. https://www.berkeleycitycollege.edu/wp/fye/

Boda, P., \& Weiser, G. (2018). Using POGILs and Blended Learning to Challenge Preconceptions of Student Ability in Introductory Chemistry. Journal of College Science Teaching, 48(1), 60-67.

Boggs, G. R. (2004). Community colleges in a perfect storm. Change: The Magazine of Higher Learning, 36(6), 6-11.

Bonet, G., \& Walters, B. R. (2016). High impact practices: Student engagement and retention. College Student Journal, 50(2), 224-235.

Bragg, D. D. (2001). Community college access, mission, and outcomes: Considering intriguing intersections and challenges. Peabody Journal of Education, 76(1), 93116.

Brame, C., \& Director, C. A. (2016). Active learning. Vanderbilt University Center for Teaching. https://cft.vanderbilt.edu/active-learning/ 
Brandenburg, R., \& Gervasoni, A. (2012). Rattling the Cage: Moving beyond ethical standards to ethical praxis in self-study research. Studying Teacher Education, 8(2), 183-191.

Bridges, C. D. (2015). Experiences Teaching Stoichiometry to Students in Grades 10 and 11. [Doctoral dissertation, Walden University]. Walden University ScholarWorks.

Brownell, S. E., \& Tanner, K. D. (2012). Barriers to faculty pedagogical change: lack of training, time, incentives, and tensions with professional identity? CBE-Life Sciences Education, 11(4), 339-346.

California Community Colleges. (2018). Student Success Scorecard. Student Success Initiative. https://scorecard.cccco.edu/

California Community Colleges (2018), What is AB 705? https://assessment.cccco.edu/ab-705-implementation

Carr, K. (2002). Building bridges and crossing borders: Using service learning to overcome cultural barriers to collaboration between science and education departments. School Science and Mathematics, 102(6), 285-298.

Chan, E. Y. M. (2012). The transforming power of narrative in teacher education. Australian Journal of Teacher Education, 37(3), 111-127.

Chen, R. (2012). Institutional characteristics and college student dropout risks: A multilevel event history analysis. Research in Higher Education, 53(5), 487-505.

Chen, X., \& Soldner, M. (2014). STEM Attrition: College Students' Paths Into and Out of STEM fields. National Center for Education Statistics. https://files.eric.ed.gov/fulltext/ED544470.pdf 
Christians, C. G., \& Carey, J. W. (1989). The logic and aims of qualitative research. In G. H. Stempel \& B. H. Westley (Eds.), Research methods in mass communication (2nd ed., pp. 354-374). Prentice Hall.

Cole, A. L., \& Knowles, J. G. (2005). The self-study of teacher education practices and the reform of teacher education. Reconceptualizing teaching practice: Developing competence through self-study (pp. 251-277). Routledge.

Darling-Hammond, L. (2015). The flat world and education: How America's commitment to equity will determine our future. Teachers College Press.

Dewey, J. (1933). How we think: A restatement of the relation of reflective thinking to the educative process. DC Heath.

Dierks, W., Weninger, J., \& Herron, J. D. (1985). Mathematics in the chemistry classroom. Part 1. The special nature of quantity equations. Journal of Chemical Education, 62(10), 839-841.

Emdin, C. (2011). Dimensions of communication in urban science education: Interactions and transactions. Science Education, 95(1), 1-20.

Evans, K. L., Yaron, D., \& Leinhardt, G. (2008). Learning stoichiometry: A comparison of text and multimedia formats. Chemistry Education Research and ractice, 9(3), 208-218.

Exline, J. J., Lisan, A. M., \& Lisan, E. R. (2012). Reflecting on acts of kindness toward the self: Emotions, generosity, and the role of social norms. The Journal of Positive Psychology, 7(1), 45-56. 
Fach, M., De Boer, T., \& Parchmann, I. (2007). Results of an interview study as basis for the development of stepped supporting tools for stoichiometric problems. Chemistry Education Research and Practice, 8(1), 13-31.

Felder, R. M., \& Brent, R. (1996). Navigating the bumpy road to student-centered instruction. College teaching, 44(2), 43-47.

Felder, R. M., \& Brent, R. (2009). Active learning: An introduction. ASQ higher education brief, 2(4), 1-5.

Fletcher, T., \& Bullock, S. M. (2012). Enacting literacy pedagogies: A collaborative selfstudy by teacher educators in physical education and science. Studying Teacher Education, 8(1), 19-33.

Freeman, S., Eddy, S. L., McDonough, M., Smith, M. K., Okoroafor, N., Jordt, H., \& Wenderoth, M. P. (2014). Active learning increases student performance in science, engineering, and mathematics. Proceedings of the National Academy of Sciences, 111(23), 8410-8415.

Fulton, K., \& Britton, T. (2011). STEM Teachers in Professional Learning Communities: From Good Teachers to Great Teaching. National Commission on Teaching and America's Future. http://www.wested.org/online_pubs/1098-executivesummary.pdf

Gallagher, T., Griffin, S., Parker, D. C., Kitchen, J., \& Figg, C. (2011). Establishing and sustaining teacher educator professional development in a self-study community of practice: Pre-tenure teacher educators developing professionally. Teaching and teacher education, 27(5), 880-890. 
Garcia, M. (2010). When Hispanic students attempt to succeed in college, but do not. Community College Journal of Research and Practice, 34(10), 839-847.

Gasiewski, J. A., Eagan, M. K., Garcia, G. A., Hurtado, S., \& Chang, M. J. (2012). From gatekeeping to engagement: A multicontextual, mixed method study of student academic engagement in introductory STEM courses. Research in higher education, 53(2), 229-261.

Gay, G. (2002). Preparing for culturally responsive teaching. Journal of teacher education, 53(2), 106-116.

Godwin, A., \& Potvin, G. (2017). Pushing and pulling Sara: A case study of the contrasting influences of high school and university experiences on engineering agency, identity, and participation. Journal of Research in Science Teaching, 54(4), 439-462.

Goldfien, A. C., \& Badway, N. N. (2014). Engaging faculty for innovative STEM bridge programs. Community College Journal of Research and Practice, 38(2-3), $122-$ 130.

Gower, D.M., Daniels, D.J. \& Lloyd, G. (1977). Hierarchies among the concepts which underlie the mole. School Science Review, 59(207), 285-299.

Graham, M. J., Frederick, J., Byars-Winston, A., Hunter, A. B., \& Handelsman, J. (2013). Increasing persistence of college students in STEM. Science, 341(6153), 14551456. 
Graham, S., \& Nevarez, C. (2017). Transformative leadership: A multicultural platform for advancing African American male student success. Journal of African American Males in Education, 8(2), 67-77.

Guthrie, J.M. (1991). Proportional Reasoning in the Solution of Problems in High School Chemistry and its Impact on Developing Critical Thinking Skills. [Master's Practicum, Nova University]. ERIC Document Reproduction Service.

Hand, B., Yang, O. E. M., \& Bruxvoort, C. (2007). Using writing-to-learn science strategies to improve year 11 students' understandings of stoichiometry. International Journal of Science and Mathematics Education, 5(1), 125-143.

Hill, M. L. (2009). Wounded healing: Forming a storytelling community in hip-hop lit. Teachers College Record, 111(1), 248-293.

Hudley, A. H. C., \& Mallinson, C. (2017). "It's worth our time": A model of culturally and linguistically supportive professional development for K-12 STEM educators. Cultural Studies of Science Education, 12(3), 637-660.

Humerick, R. (2002). Effective strategies for active learning in the small chemistry classroom or laboratory. In P. C. Taylor, P. J. Gilmer, \& K. Tobin (Eds.), Transforming undergraduate science teaching: Social constructivist perspectives (pp. 211-230). Peter Lang Publishing, Inc.

Hurtado, S., Eagan, M. K., Tran, M. C., Newman, C. B., Chang, M. J., \& Velasco, P. (2011). "We do science here": Underrepresented students' interactions with faculty in different college contexts. Journal of Social Issues, 67(3), 553-579. 
Jackson, F. R. (1993). Seven strategies to support a culturally responsive pedagogy. Journal of Reading, 37(4), 298-303.

Johnson, R. T., \& Johnson, D. W. (2008). Active learning: Cooperation in the classroom. The annual report of educational psychology in Japan, 47, 29-30.

Kezar, A., \& Maxey, D. (2014). Faculty matter: So why doesn't everyone think so. Thought \& Action. https:/www.nea.org/assets/docs/HE/e-Kezar.pdf

Kothiyal, A., Majumdar, R., Murthy, S., \& Iyer, S. (2013, August). Effect of think-pairshare in a large CS1 class: $83 \%$ sustained engagement. In Proceedings of the ninth annual international ACM conference on International computing education research (pp. 137-144). ACM.

Ladson-Billings, G. (1995). Toward a theory of culturally relevant pedagogy. American educational research journal, 32(3), 465-491.

Leopold, D. G., \& Edgar, B. (2008). Degree of mathematics fluency and success in second-semester introductory chemistry. Journal of Chemical Education, 85(5), 724-731.

Lloyd, P. M., \& Eckhardt, R. A. (2010). Strategies for Improving Retention of Community College Students in the Sciences. Science Educator, 19(1), 33-41.

Lom, B. (2012). Classroom activities: simple strategies to incorporate student-centered activities within undergraduate science lectures. Journal of Undergraduate Neuroscience Education, 11(1), A64-A71. 
Long, S., Souto-Manning, M., \& Vasquez, V. (Eds.). (2016). Courageous leadership in early childhood education: Taking a stand for social justice. Teachers College Press.

LoPresto, M. C., \& Slater, T. F. (2016). A new comparison of active learning strategies to traditional lectures for teaching college astronomy. Journal of Astronomy \& Earth Sciences Education, 3(1), 59-76.

Loughran, J. (2005). Researching teaching about teaching: Self-study of teacher education practices. Studying teacher education, 1(1), 5-16.

Malcom S, Feder M (2016). Barriers and Opportunities for 2-Year and 4-Year STEM Degrees: Systemic Change to Support Students'Diverse Pathways. National Academies Press.

Marshall, E., \& Toohey, K. (2010). Representing family: Community funds of knowledge, bilingualism, and multimodality. Harvard Educational Review, 80(2), 221-242.

Megowan-Romanowicz, C. (2010). Inside out: Action research from the teacherresearcher perspective. Journal of Science Teacher Education, 21(8), 993-1011.

Mesa, V., Celis, S., \& Lande, E. (2014). Teaching approaches of community college mathematics faculty: Do they relate to classroom practices? American Educational Research Journal, 51(1), 117-151.

Morrison, K. A., Robbins, H. H., \& Rose, D. G. (2008). Operationalizing culturally relevant pedagogy: A synthesis of classroom-based research. Equity \& Excellence in Education, 41(4), 433-452. 
Murphy, D. (2016). Making Voices Visible: Using Visual Data in Teacher Education and Research. New Directions for Teaching and Learning, (pp. 57-66). Wiley.

Musu-Gillette, L., de Brey, C., McFarland, J., Hussar, W., Sonnenberg, W., \& Wilkinson-Flicker, S. (2017). Status and Trends in the Education of Racial and Ethnic Groups 2017. National Center for Education Statistics. https://nces.ed.gov/pubs2017/2017051.pdf

Musu-Gillette, L., Robinson, J., McFarland, J., KewalRamani, A., Zhang, A., \& Wilkinson-Flicker, S. (2016). Status and Trends in the Education of Racial and Ethnic Groups 2016. National Center for Education Statistics.

https://nces.ed.gov/pubs2016/2016007.pdf

Nieto, S., \& Irizarry, J. (2012). Instructional practices and approaches. Association of Mexican American Educators Journal, 6(3), 17-21.

NSF (n.d.). Earned associate's degrees, by citizenship, field, race, and ethnicity: 200015. National Science Board. https://www.nsf.gov/statistics/2018/nsb20181/assets/561/tables/at02-19.pdf NSF (n.d.). Women, Minorities, and Persons with Disabilities in Science and Engineering. National Science Foundation. https://www.nsf.gov/statistics/2017/nsf17310/data.cfm

Okanlawon, A. E. (2008). The modified GRASS model: an alternate path to solve complex stoichiometric problems. Journal of Turkish Science Education, 5(2), 1226. 
O'Keeffe, P. (2013). A sense of belonging: Improving student retention. College Student Journal, 47(4), 605-613.

Palmer, R. T., Davis, R. J., Moore III, J. L., \& Hilton, A. A. (2010). A nation at risk: Increasing college participation and persistence among African American males to stimulate US global competitiveness. Journal of African American Males in Education, 1, 105-124.

Palmer, R. T., Maramba, D. C., \& Dancy, T. E. (2011). A qualitative investigation of factors promoting the retention and persistence of students of color in STEM. The Journal of Negro Education, 80(4), 491-504.

Perez, T., Cromley, J. G., \& Kaplan, A. (2014). The role of identity development, values, and costs in college STEM retention. Journal of educational psychology, 106(1), 315-329.

Pitner, R. O., \& Sakamoto, I. (2005). The role of critical consciousness in multicultural practice: Examining how its strength becomes its limitation. American Journal of Orthopsychiatry, 75(4), 684-694.

Pitre, C. C. (2014). Improving African American student outcomes: Understanding educational achievement and strategies to close opportunity gaps. Western Journal of Black Studies, 38(4), 209-217.

Powell, M. (2012). Writing without inhibition: Students and their teacher explore research in their communities. Journal of Teaching Writing, 27(1), 67-90.

Quijano, A. (2007). Coloniality and modernity/rationality. Cultural studies, 21(2-3), 168178. 
Redman, E. (2013). Advancing Educational Pedagogy for Sustainability: Developing and Implementing Programs to Transform Behaviors. International journal of environmental and science education, 8(1), 1-34.

Reed, B. G., Newman, P. A., Suarez, Z. E., \& Lewis, E. A. (1997). Interpersonal practice beyond diversity and toward social justice: The importance of critical consciousness. Interpersonal Practice in Social Work. $3 d$ ed. Boston: Allyn and Bacon, 44-78.

Reznitskaya, A., \& Gregory, M. (2013). Student thought and classroom language: Examining the mechanisms of change in dialogic teaching. Educational Psychologist, 48(2), 114-133.

Rissanen, A. (2018). Student Engagement in Large Classroom: the Effect on Grades, Attendance and Student Experiences in an Undergraduate Biology Course. Canadian Journal of Science, Mathematics and Technology Education, 18(2), 136-153.

Rocca, K. A. (2010). Student participation in the college classroom: An extended multidisciplinary literature review. Communication education, 59(2), 185-213.

Saldaña, J. (2015). The coding manual for qualitative researchers. Thousand Oaks, CA: Sage.

Samaras, A. P., Hicks, M. A., \& Berger, J. G. (2004). Self-study through personal history. International handbook of self-study of teaching and teacher education practices (pp. 905-942). Springer, Dordrecht. 
Samuel, K. R., \& Scott, J. A. (2014). Promoting Hispanic Student Retention in Two Texas Community Colleges. Research in Higher Education Journal, 25, 1-12.

Scott, F. J. (2012). Is mathematics to blame? An investigation into high school students' difficulty in performing calculations in chemistry. Chemistry Education Research and Practice, 13(3), 330-336.

Scott, G. A. (2008). Workforce development: Community colleges and one-stop centers collaborate to meet 21 st century workforce needs. DIANE Publishing.

Seglem, R., \& Garcia, A. (2015). "So we have to teach them or what?": Introducing Preservice teachers to the figured worlds of urban youth through digital conversation. Teachers College Record, 117(3), 1-34.

Seidman, A. (2005). Minority student retention: Resources for practitioners. New directions for institutional research, 2005(125), 7-24.

Seidman, I. (2013). Interviewing and qualitative research: A guide for researchers in education and the social sciences $\left(4^{\text {th }}\right.$ ed.). Teachers College Press.

Shields, C. M. (2010). Transformative leadership: Working for equity in diverse contexts. Educational administration quarterly, 46(4), 558-589.

So, A. Y. (1990). Social change and development: Modernization, dependency and world-system theories. Sage.

Strayhorn, T. L. (2015). Factors influencing Black males' preparation for college and success in STEM majors: A mixed methods study. Western Journal of Black Studies, 39(1), 45-63. 
Talanquer, V., \& Pollard, J. (2017). Reforming a large foundational course: Successes and challenges. Journal of Chemical Education, 94(12), 1844-1851.

Tanner, K. D. (2013). Structure matters: twenty-one teaching strategies to promote student engagement and cultivate classroom equity. CBE-Life Sciences Education, 12(3), 322-331.

Torres, M. N., \& Mercado, M. (2004). Living the Praxis of Teacher Education through Teacher Research. Scholar-Practitioner Quarterly, 2(2), 59-73.

Trimbur, J. (1989). Consensus and difference in collaborative learning. College English, 51(6), 602-616.

Vanassche, E., \& Kelchtermans, G. (2016). Facilitating self-study of teacher education practices: Toward a pedagogy of teacher educator professional development. Professional development in education, 42(1), 100-122.

Warwick, P., Vrikki, M., Vermunt, J. D., Mercer, N., \& van Halem, N. (2016). Connecting observations of student and teacher learning: an examination of dialogic processes in Lesson Study discussions in mathematics. ZDM Mathematics Education, 48(4), 555-569.

Watkins, J., \& Mazur, E. (2013). Retaining students in science, technology, engineering, and mathematics (STEM) majors. Journal of College Science Teaching, 42(5), $36-41$.

Widanski, B. B., \& McCarthy, W. C. (2009). Assessment of chemistry anxiety in a twoyear college. Journal of Chemical Education, 86(12), 1447-1449. 
Williams, J., \& Ritter, J. K. (2010). Constructing new professional identities through selfstudy: From teacher to teacher educator. Professional development in education, 36(1-2), 77-92.

Willingham, D. T. (2003). Students remember what they think about. American Educator, 27(2), 37-41.

Witt, P. L., Schrodt, P., Wheeless, V. E., \& Bryand, M. C. (2014). Students' intent to persist in college: Moderating the negative effects of receiver apprehension with instructor credibility and nonverbal immediacy. Communication Studies, 65(3), $330-352$.

Zeichner, K. (2002). Beyond traditional structures of student teaching. Teacher Education Quarterly, 29(2), 59-64.

Zeichner, K. M., \& Liston, D. P. (2013). Reflective teaching: An introduction. Routledge.

Zepke, N., \& Leach, L. (2010). Improving student engagement: Ten proposals for action. Active learning in higher education, 11(3), 167-177.

Zumdahl, S. S., \& DeCoste, D. J. (2018). Introductory chemistry: A foundation. Cengage learning. 


\section{APPENDICES}

\section{APPENDIX A}

Pretest Survey

For each statement below, circle the response that best characterizes your perception.

\begin{tabular}{|c|c|c|c|c|c|}
\hline Interactive Strategies & $\begin{array}{l}\text { Strongly } \\
\text { Disagree }\end{array}$ & Disagree & $\begin{array}{l}\text { Neither } \\
\text { Agree nor } \\
\text { Disagree }\end{array}$ & Agree & $\begin{array}{l}\text { Strongly } \\
\text { Agree }\end{array}$ \\
\hline $\begin{array}{l}\text { I appreciate Chemistry in } \\
\text { my daily life. }\end{array}$ & 1 & 2 & 3 & 4 & 5 \\
\hline $\begin{array}{l}\text { I identify myself as a } \\
\text { science student. }\end{array}$ & 1 & 2 & 3 & 4 & 5 \\
\hline $\begin{array}{l}\text { High School Chemistry } \\
\text { has prepared me well for } \\
\text { this class. }\end{array}$ & 1 & 2 & 3 & 4 & 5 \\
\hline $\begin{array}{l}\text { Coming to this class, I } \\
\text { feel strongly about my } \\
\text { potential for success. }\end{array}$ & 1 & 2 & 3 & 4 & 5 \\
\hline
\end{tabular}

What are your expectations from your Chem 30A professor? 


\section{APPENDIX B}

\section{Posttest Survey}

For each statement below, circle the response that best characterizes your perception.

\begin{tabular}{lccccc}
\hline \multicolumn{1}{c}{ Interactive Strategies } & $\begin{array}{c}\text { Strongly } \\
\text { Disagree }\end{array}$ & Disagree & $\begin{array}{c}\text { Neither } \\
\text { Agree nor } \\
\text { Disagree }\end{array}$ & Agree & $\begin{array}{c}\text { Strongly } \\
\text { Agree }\end{array}$ \\
\hline $\begin{array}{l}\text { I appreciate Chemistry in } \\
\text { my daily life. }\end{array}$ & 1 & 2 & 3 & 4 & 5 \\
$\begin{array}{l}\text { I identify myself as a } \\
\text { science student. }\end{array}$ & 1 & 2 & 3 & 4 & 5 \\
$\begin{array}{l}\text { This class has prepared } \\
\text { me well for the next } \\
\text { class. }\end{array}$ & 1 & 2 & 3 & 4 & 5 \\
$\begin{array}{l}\text { After taking this class, I } \\
\text { feel strongly about my } \\
\text { potential for success. }\end{array}$ & 1 & 2 & 3 & 4 & 5 \\
\hline
\end{tabular}

What do you advise your Chemistry professors to modify their pedagogy to help you learn better? 


\section{APPENDIX C}

\section{Exit Ticket - Interactive Strategies}

Dialogic pedagogy is where the instructor interacts with students during the lecture.

Think-Pair-Share is when you think about the problem, pair up with a neighbor, and then share the solution.

Working on Worksheets together is when you work in collaboration small groups to solve a problem or set of problems.

For each strategy used by your instructor, circle the response that best characterizes how you feel about the impact of the strategy on your academic learning.

\begin{tabular}{lccccc}
\hline Interactive Strategies & $\begin{array}{c}\text { Strongly } \\
\text { Disagree }\end{array}$ & Disagree & $\begin{array}{c}\text { Neither Agree } \\
\text { nor Disagree }\end{array}$ & Agree & $\begin{array}{c}\text { Strongly } \\
\text { Agree }\end{array}$ \\
\hline Dialogic pedagogy & 1 & 2 & 3 & 4 & 5 \\
Think-Pair-Share & 1 & 2 & 3 & 4 & 5 \\
$\begin{array}{l}\text { Working on } \\
\text { Worksheets together }\end{array}$ & 1 & 2 & 3 & 4 & 5 \\
\end{tabular}

Describe one thing in lecture today that helped you the most in your engagement. 


\section{APPENDIX D}

\section{Focus Group Interview Questions}

1. Tell me about the process of coming to understand the concept, which I covered last week.

2. Which interactive strategy do you believe supported you most in your learning?

3. Describe the classroom environment that helps you learn better.

4. What do you expect from your instructor about his or her demeanor in the class and how does it affect your learning?

Note: I am using semi-structured interview protocol. I will ask other questions that are relevant. 


\section{APPENDIX E}

\section{Stoichiometry Worksheet}

Circle the best choice. Explain the process how you came up with the final answer.

1. How many grams are in a 6.94 mol sample of sodium hydroxide?
a) $40.0 \mathrm{~g}$
b) $278 \mathrm{~g}$
c) $169 \mathrm{~g}$
d) $131 \mathrm{~g}$

2. A sample of ammonia has a mass of $56.6 \mathrm{~g}$. How many molecules are in this sample?
a) 3.32 molecules
b) $17.03 * 10^{24}$ molecules
c) $6.78 * 10^{23}$ molecules
d) $2.00 * 10^{24}$ molecules

3. How many atoms of hydrogen are present in $6.0 \mathrm{~g}$ of water?
a) $2.0 \times 10^{23}$
b) $7.2 \times 10^{24}$
c) $1.1 \times 10^{24}$
d) $4.0 \times 10^{23}$

4. A $6.32 \mathrm{~g}$ sample of potassium chlorate was decomposed to release oxygen gas. How many moles of oxygen are formed?
a) $1.65 \mathrm{~g}$
b) 0.051 moles
c) 0.0344 moles
d) 0.0774 moles

5. Consider the following reaction: $\quad \mathrm{CH}_{4}(\mathrm{~g})+4 \mathrm{Cl}_{2}(\mathrm{~g}) \rightarrow \mathrm{CCl}_{4}(\mathrm{~g})+4 \mathrm{HCl}(\mathrm{g})$ What mass of $\mathrm{CCl}_{4}$ will be formed if 1.60 moles of chlorine react with excess of methane? Which substance is the limiting reagent?
a) $229 \mathrm{~g}$
b) $171 \mathrm{~g}$
c) $114 \mathrm{~g}$
d) $61.5 \mathrm{~g}$ 
6. When $125.0 \mathrm{~g}$ of ethylene $\left(\mathrm{C}_{2} \mathrm{H}_{4}\right)$ burns in oxygen to give carbon dioxide and water, how many grams of $\mathrm{CO}_{2}$ are formed? Which substance is the limiting reactant?
a) $392.1 \mathrm{~g}$
b) $250.0 \mathrm{~g}$
c) $57.50 \mathrm{~g}$
d) $425.6 \mathrm{~g}$

7. A $5.95 \mathrm{~g}$ sample of $\mathrm{AgNO}_{3}$ is reacted with $\mathrm{BaCl}_{2}$. Which compound is a limiting reagent? What is the percent yield of $\mathrm{AgCl}$ formed?
a) $21.4 \%$
b) $39.8 \%$
c) $67.2 \%$
d) $79.7 \%$ 